\title{
Effects of Synbiotics on the Fecal Microbiome and Metabolomic Profiles of Healthy Research Dogs Administered Antibiotics: A Randomized, Controlled Trial
}

\section{OPEN ACCESS}

Edited by:

Micaela Sgorbini,

University of Pisa, Italy

Reviewed by:

Giuseppe Conte,

University of Pisa, Italy

Shaqiu Zhang,

Sichuan Agricultural University, China

*Correspondence: Jacqueline C. Whittemore

jwhittemore@utk.edu

Specialty section:

This article was submitted to Comparative and Clinical Medicine, a section of the journal

Frontiers in Veterinary Science

Received: 08 February 2021 Accepted: 19 April 2021

Published: 26 May 2021

Citation:

Whittemore JC, Price JM, Moyers T and Suchodolski JS (2021) Effects of Synbiotics on the Fecal Microbiome and Metabolomic Profiles of Healthy

Research Dogs Administered

Antibiotics: A Randomized, Controlled

Trial. Front. Vet. Sci. 8:665713.

doi: 10.3389/fvets.2021.665713

\author{
Jacqueline C. Whittemore ${ }^{1 *}$, Joshua M. Price ${ }^{2}$, Tamberlyn Moyers ${ }^{1}$ and \\ Jan S. Suchodolski ${ }^{3}$ \\ ${ }^{1}$ Small Animal Clinical Sciences, College of Veterinary Medicine, University of Tennessee, Knoxville, TN, United States, \\ ${ }^{2}$ Office of Information Technology, University of Tennessee, Knoxville, TN, United States, ${ }^{3}$ The Gastrointestinal Laboratory, \\ Small Animal Clinical Sciences, Texas A\&M University, College Station, TX, United States
}

Background: Antibiotic-associated gastrointestinal signs occurred in $100 \%$ of dogs administered enrofloxacin with metronidazole in a previous study, and signs partially were mitigated by synbiotics. The objective of this randomized, double-blinded, placebo-controlled trial was to compare the fecal microbiome and metabolome of dogs administered enrofloxacin and metronidazole, followed by either a placebo or a bacterial/yeast synbiotic combination.

Methods: Twenty-two healthy research dogs were randomized to two treatment groups. There were three study periods: baseline, treatment, and washout. Dogs were administered enrofloxacin (10 mg/kg qd) and metronidazole (12.5 mg/kg BID), followed $1 \mathrm{~h}$ later by placebo or a commercially-available synbiotic combination (BID), per os for 21 days with reevaluation 56 days thereafter. Fecal samples were collected on days 5-7 (baseline), 26-28, and 82-84. The fecal microbiome was analyzed by qPCR and sequencing of $16 \mathrm{~S}$ rRNA genes; time-of-flight mass spectrometry was used to determine metabolomic profiles. Split plot repeated measures mixed model ANOVA was used to compare results between treatment groups. $P<0.05$ was considered significant, with Benjamini and Hochberg's False Discovery Rate used to adjust for multiple comparisons.

Results: Alpha diversity metrics differed significantly over time in both treatment groups, with incomplete recovery by days $82-84$. Beta diversity and the dysbiosis index differed significantly over time and between treatment groups, with incomplete recovery at days 82-84 for dogs in the placebo group. Significant group-by-time interactions were noted for 15 genera, including Adlercreutzia, Bifidobacterium, Slackia, Turicibacter, Clostridium (including C. hiranonis) [Ruminococcus], Erysipelotrichaceae_g_, [Eubacterium], and Succinivibrionaceae_g_. Concurrent group and time effects were present for six genera, including Collinsella, Ruminococcaceae_g_, and Prevotella. Metabolite profiles differed significantly by group-by-time, group, and time for 28, 20, and 192 metabolites, respectively. These included short-chain fatty acid, bile acid, tryptophan, sphingolipid, benzoic acid, and cinnaminic acid metabolites, as well as fucose and ethanolamine. Changes in many taxa and metabolites persisted through days 82-84. 
Conclusion: Antibiotic administration causes sustained dysbiosis and dysmetabolism in dogs. Significant group-by-time interactions were noted for a number of taxa and metabolites, potentially contributing to decreased antibiotic-induced gastrointestinal effects in dogs administered synbiotics.

Keywords: antibiotic-associated diarrhea, dysbiosis, deoxycholic acid, D-erythro-sphingosine, bile acid diarrhea, probiotic, indole, propanediol

\section{INTRODUCTION}

Adverse antibiotic-induced gastrointestinal signs (AAGS) have been described in a variety of species, including people, cats, and dogs (1-5). Clinical signs are believed to stem primarily from derangement of the gastrointestinal microbiome, with broad-spectrum antibiotic regimens associated with an increased risk of AAGS (1). Administration of synbiotics, commercial combinations of probiotics and prebiotics, $1 \mathrm{~h}$ after antibiotic administration significantly decreases the occurrence and severity of AAGS in healthy cats and dogs $(2,5)$.

Marked reductions in fecal alpha and beta diversity have been identified during antibiotic administration in cats (4, 6) and dogs (7), with derangements in individual taxa and metabolite profiles identified up to 603 days after antibiotic discontinuation in cats. Furthermore, derangements significantly differed between cats administered antibiotics with a placebo vs. a synbiotic, as did the development of AAGS, suggesting a potential mechanism for AAGS reduction. The purpose of this randomized, double-blinded, placebo-controlled trial was to characterize and compare changes in the fecal microbiome and metabolomic profiles of healthy research dogs administered enrofloxacin and metronidazole, followed $1 \mathrm{~h}$ later by either a placebo or a bacterial/yeast synbiotic combination.

\section{MATERIALS AND METHODS \\ Study Design}

Fecal samples collected during the first phase of a previously reported randomized, double-blinded, placebo-controlled, 2way, 2-period, cross-over study with a 8 -week washout period (5) were used for this study (Figure 1). The study protocol was approved by the Institutional Animal Care and Use Committee of the University of Tennessee, Knoxville (protocol number 2544) and performed in compliance with "The Guide for the Care and Use of Laboratory Animals" in laboratory animal facilities that are AAALAC certified and exceed NIH standards of care.

Briefly, 22 healthy research dogs, randomized using a random number sequence to two treatment groups after stratification by breed, were included in the study. Each group contained 11 dogs: six female intact hound dogs and five male castrated beagles. All dogs were 1 year old. Median weight was $9.3 \mathrm{~kg}$ (range, $7.3-21.0 \mathrm{~kg}$ ) for dogs in the placebo group and $9.3 \mathrm{~kg}$ (range, $7.8-18.5 \mathrm{~kg}$ ) for dogs in the synbiotic group.

After a 1-week baseline, each dog was administered study medications for 21 days. Each dog received enrofloxacin (Baytril Taste Tabs ${ }^{\circledR}$, Catalog\# 08711391 and 08711405 , Bayer
Corporation, Shawnee Mission, KS, USA) $10 \mathrm{mg} / \mathrm{kg}$ q24h and metronidazole (Teva Pharmaceuticals USA, Inc., NDC\# 501110333 , North Wales, PA, USA) $12.5 \mathrm{mg} / \mathrm{kg}$ q12h per os in $13 \mathrm{gm}$ of canned commercial dog food, after which each dog was given its ration of commercial dry dog food. One hour after antibiotic administration, each dog was administered two chewable tablets per os, containing either placebo or the probiotic/synbiotic combination as per group assignment. The probiotic/synbiotic combination consisted of one chewable multi-strain bacterial probiotic tablet (Proviable ${ }^{\circledR}$-Forte, Catalog\# PROVFTCHW180, Nutramax Laboratories Veterinary Sciences, Inc., Lancaster, SC, USA) plus one chewable yeast synbiotic tablet (Mycequin ${ }^{\circledR}$, Catalog\# MYCEQUIN144, Nutramax Laboratories Veterinary Sciences, Inc., Lancaster, SC, USA). Each tablet of the probiotic was formulated to contain $1 \times 10^{10} \mathrm{cfu}$ of a proprietary mixture of Bifidobacterium bifidum, Enterococcus faecium, Streptococcus thermophilus, and Lactobacillus acidophilus, bulgaricus, casei, and plantarum. Each tablet of the synbiotic was formulated to contain $1 \times 10^{10} \mathrm{cfu}$ of a proprietary strain of Saccharomyces boulardii and the prebiotic beta-glucan. Placebo tablets, provided by the manufacturer, did not differ in shape, size, smell, or flavoring from the probiotic and synbiotic tablets.

\section{Fecal Samples}

First morning naturally-voided fecal samples were collected daily for 3 days from each dog at each time point (days 5-7, 26-28, and $82-84)$ to minimize the effects of daily variation and differential distribution of bacterial groups and metabolites within individual fecal samples on results. A 2-g sample was taken from the center portion of each fecal sample and subdivided into two aliquots, placed into individual $2 \mathrm{~mL}$ cryovials, and immediately frozen at $-80^{\circ} \mathrm{C}$ pending completion of data collection. Samples for each dog from each time point (days 5-7, 26-28, and 82-84) were combined directly prior to sample analysis to generate pooled samples for microbiome and metabolomic analysis.

One dog in the placebo group was removed from treatment after 1 week of antibiotics due to excessive weight loss with associated hyporexia and vomiting. As a result, fecal samples from only 10 dogs in the placebo group were available for days $26-28$.

\section{Microbiome Analysis}

Fecal microbiome analysis was performed as per a previous study (7). To summarize, genomic DNA was extracted from $100 \mathrm{mg}$ of feces from each pooled sample using a commercially available kit according to manufacturer's protocol (PowerSoil $^{\circledR}$, Catalog \#12888-100, Mo Bio Laboratories, 


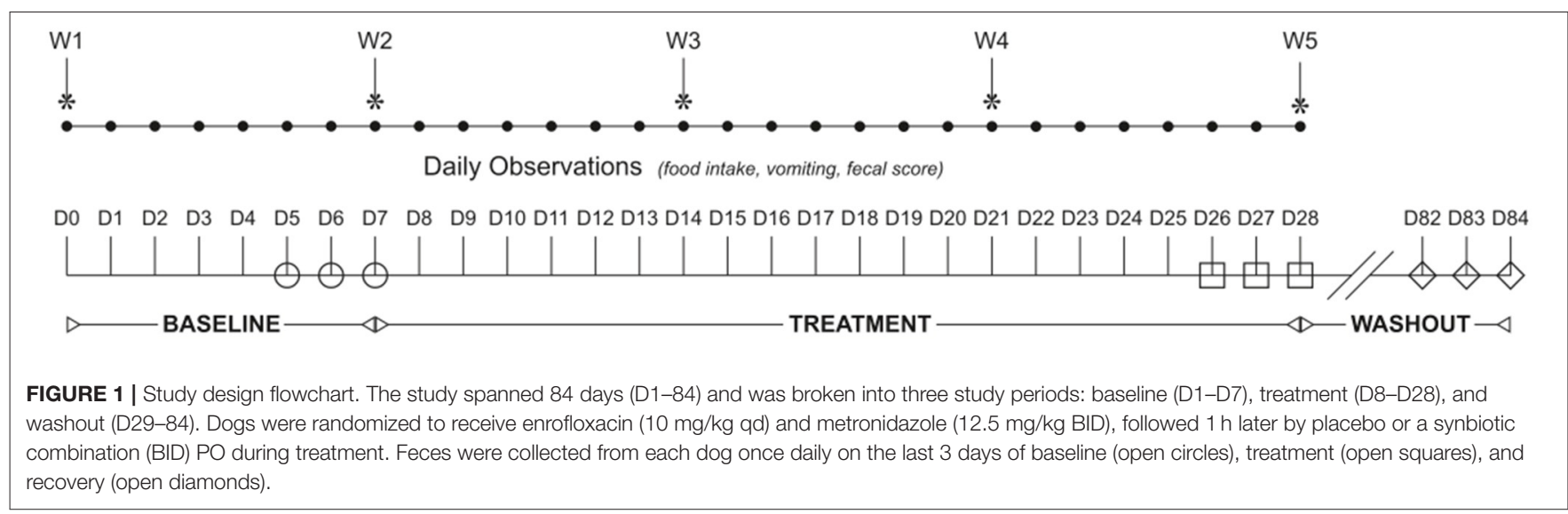

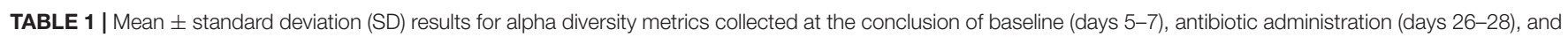

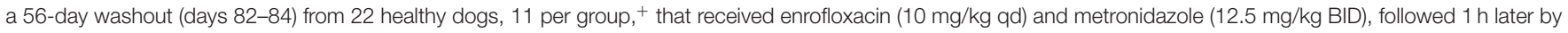
placebo or a synbiotic combination (BID) PO for 21 days.

\begin{tabular}{|c|c|c|c|c|c|c|c|}
\hline & \multicolumn{2}{|c|}{ Baseline } & \multicolumn{2}{|c|}{ Days 26-28 } & \multicolumn{2}{|c|}{ Days 82-84 } & \multirow[t]{2}{*}{$P$-value } \\
\hline & Placebo & Synbiotic & Placebo & Synbiotic & Placebo & Synbiotic & \\
\hline $\begin{array}{l}\text { Shannon } \\
\text { index }\end{array}$ & $6.0 \pm 0.2^{a}$ & $5.7 \pm 0.4^{a}$ & $5.4 \pm 0.2^{\mathrm{C}}$ & $5.4 \pm 0.2^{\mathrm{C}}$ & $5.7 \pm 0.1^{b}$ & $5.7 \pm 0.2^{\mathrm{b}}$ & $<0.001$ (time) \\
\hline $\begin{array}{l}\text { Pielou } \\
\text { evenness }\end{array}$ & $\begin{array}{l}0.9422 \pm \\
0.0082^{b}\end{array}$ & $\begin{array}{l}0.9395 \pm \\
0.0138^{b}\end{array}$ & $\begin{array}{l}0.9452 \pm \\
0.0064^{\mathrm{b}}\end{array}$ & $\begin{array}{c}0.9541 \pm \\
0.0081^{a}\end{array}$ & $\begin{array}{l}0.9461 \pm \\
0.0071^{b}\end{array}$ & $\begin{array}{l}0.9427 \pm \\
0.0077^{b}\end{array}$ & $\begin{array}{c}0.007 \text { (time), } 0.043 \\
\text { (group by time) }\end{array}$ \\
\hline Chao1 metric & $80.0 \pm 9.1^{a}$ & $69.4 \pm 14.7^{a}$ & $52.5 \pm 8.9^{c}$ & $50.9 \pm 5.7^{c}$ & $63.5 \pm 5.0^{\mathrm{b}}$ & $64.3 \pm 8.0^{b}$ & $<0.001$ (time) \\
\hline
\end{tabular}

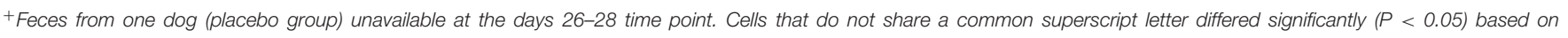
post-hoc analysis.

Carlsbad, CA, USA). Amplification and sequencing of the V4 variable region (primers 515F/806R) of the 16S rRNA gene was performed on a MiSeq (Illumina) at a sequencing facility [MR DNA (Molecular Research LP), Shallowater, TX, USA]. The raw sequences were analyzed using a QIIME pipeline (2018.8). Amplicon sequence variants (ASVs) were assigned using DADA and rarefied to 35,000 sequences per sample. Genomic DNA sequences were deposited in a public repository (8).

Extracted DNA was used to perform quantitative PCR for bacterial groups (total bacteria, Faecalibacterium spp., Turicibacter spp., Streptococcus spp., Escherichia coli, Blautia spp., Fusobacterium spp., Clostridium hiranonis) previously associated with dysbiosis and for calculation of the dysbiosis index (9). For these analyses, $2 \mu$ l of normalized DNA (final concentration: $5 \mathrm{ng} / \mu \mathrm{l}$ ) was combined with $5 \mu \mathrm{l}$ of a DNAbinding dye (SsoFast EvaGreen ${ }^{\circledR}$ supermix, Catalog \#17252011725205, Bio-Rad Laboratories, Hercules, CA, USA), $0.4 \mu \mathrm{l}$ each of a forward and reverse primer (final concentration: $400 \mathrm{nM}$ ), and $2.6 \mu \mathrm{l}$ of PCR water to achieve a total reaction volume of $10 \mu$ l. Data were expressed as log amount of DNA (fg) for each particular bacterial group per $10 \mathrm{ng}$ of isolated total DNA.

\section{Fecal Metabolomics}

Fecal metabolomic analysis was performed as per a previous study (4). Briefly, a metabolomics facility (West Coast Metabolomics Core, University of California, Davis, CA, USA) analyzed $10 \mathrm{mg}$ of lyophilized feces from each pooled sample using gas chromatography time-of-flight mass spectrometry and standardized protocols. ChromaTOF v. 2.32 was used to process raw data. BinBase algorithm was applied to match spectra to database compounds or characterize spectra as an unknown compound, and quantification was reported by peak height of an ion at the specific retention index characteristic of the compound across all samples. Metabolomics data were deposited in a public repository (10).

\section{Statistical Analyses}

Descriptive statistics were generated for each response measure. Samples were analyzed for normality using the Shapiro-Wilk test and for the presence of outliers using box-and-whisker plots. A dysbiosis index was calculated. Quantitative Insights Into Microbial Ecology (QIIME) scripts were used to create alpha rarefaction plots, as well as calculate measures of alpha diversity (Chao1, Shannon, Pielou Evenness, and ASVs). Beta diversity was determined using weighted and unweighted Unifrac distance metrics; principal coordinates analysis (PCoA) plots were plotted. Beta diversity across time and groups of dogs was determined using ANOSIM. Global changes in untargeted metabolomic profiles were determined using principal component analysis (PCA) plots and heatmaps. Metabolomic analysis was performed using the Homo sapiens pathway library, interquantile range data filtering, log transformation, and Pareto scaling. 
Alpha diversity metrics, the dysbiosis index, relative and absolute bacterial abundances, and fecal metabolite profiles were compared between treatment groups using split plot repeated measures mixed models ANOVAs that included fixed effects of treatment group (placebo or synbiotic), time period, and treatment group-by-time period interaction. The repeated measure of time period was accounted for in a repeated statement and random effects for dog nested within group were included. The Shapiro-Wilk test of normality of the residuals was evaluated for each marker to determine if assumption of normally distributed residuals had been met. Model assumptions regarding equality of variances were evaluated with the Levene's test for equality of variances. Box plots and studentized residuals were computed for each model to identify potential outliers. Post-hoc differences in least squares means were determined for markers with significant main effects or interaction terms. A rank transformation was applied to qPCR results and relative abundances of ASVs to provide a robust solution to deviations from statistical assumptions. Only ASVs that were present in $\geq 50 \%$ of dogs in $\geq 1$ group at $\geq 1$ time point were included in statistical analyses.

$P<0.05$ was considered statistically significant. $P$-values were corrected for multiple comparisons on each phylogenetic level and for untargeted metabolomics using the Benjamini and Hochberg's False Discovery Rate (fdr). Publicly-accessible and commercially available software packages were used for all analyses: QIIME 2. Available at: http://www.qiime.org; MetaboAnalyst 4.0. Available at: http://www.metaboanalyst.ca; PRIMER 6, PRIMER-E Ltd; and SAS 9.4 release TS1M3, SAS Institute Inc.

\section{RESULTS}

\section{Fecal Microbiome}

Alpha diversity differed significantly over time regardless of treatment group, with incomplete recovery of the Shannon index and Chao1 metric on days 82-84 (Table 1). Post-hoc analyses revealed all time points differed from one another for both the Shannon index and Chaol metrics, respectively $(P \leq 0.001$, for all). A group-by-time interaction was also present for pielou evenness; post-hoc analysis revealed this was due to significant differences between treatment groups at the conclusion of treatment (days 26-28) $(P=0.023)$. Beta diversity differed significantly over time and between treatment groups based on unweighted (Figure 2, $P=0.001, R=0.516$ ) and weighted UniFrac distances $(P=0.001, R=0.609)$. Based on unweighted distances, beta diversity was significantly different on days 26-28 compared to baseline $(P=0.001, R=0.978)$ and days 82-84 ( $P=0.001, R=0.923)$ for dogs in the synbiotic group, with no significant difference between baseline and days 82-84. Conversely, beta diversity was significantly different among all three time points for dogs in the placebo group $(P=0.001$, $R=0.482-0.620$ ). Finally, beta diversity differed slightly between treatment groups at baseline and on days 26-28 $(P=0.019-$ $0.023, R=0.130-0.132)$, whereas a more substantial difference

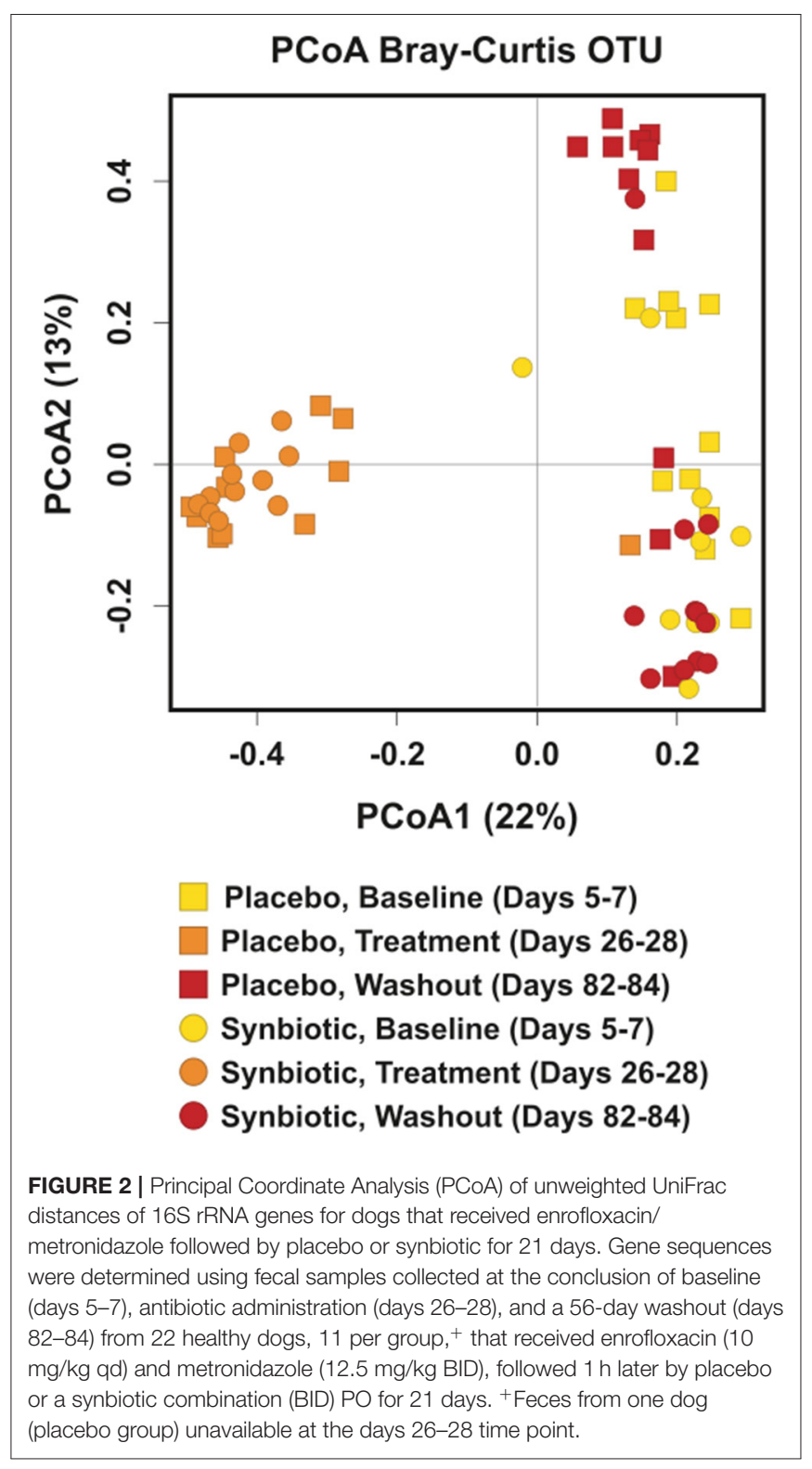

was identified between treatment groups on days $82-84$ ( $P=0.001, R=0.467)$.

Five phyla (Table 2) were identified based on sequencing analysis (mean baseline prevalences): Actinobacteria (50.54\%), Bacteroidetes (2.44\%), Firmicutes (46.12\%), Fusobacteria (0.04\%), and Proteobacteria (0.86\%). Marked and significant differences were identified among time points and between treatment groups in the fecal microbiome at all phylogenetic levels (Table 2, Supplementary Table 1). At the genus level (Table 2), significant group-by-time, time, and/or treatment group effects were noted for 33 ASVs. Group-by-time interactions were identified for 15 ASVs, whereas concurrent treatment group and time effects-but not group-by-time interactions-were present for six ASVs. Significant time effects were identified for 29 
TABLE 2 | Median (range) percent relative abundances of bacterial phyla and genera for dogs that received enrofloxacin/metronidazole followed by placebo or synbiotic for 21 days.

\begin{tabular}{|c|c|c|c|c|c|c|c|c|c|}
\hline & \multicolumn{3}{|c|}{ Placebo } & \multicolumn{3}{|c|}{ Synbiotic } & \multicolumn{3}{|c|}{ fdr $P$-value } \\
\hline & Baseline & Days 26-28 & Days 82-84 & Baseline & Days 26-28 & Days 82-84 & Group* Time & Group & Time \\
\hline Actinobacteria & $1.95^{\mathrm{C}}(0.59-4.79)$ & $8.22^{\mathrm{a}}(2.35-19.04)$ & $6.81^{\mathrm{b}}(1.35-11.46)$ & $2.71^{\mathrm{c}}(0.47-6.75)$ & $17.23^{\mathrm{a}}(2.76-20.19)$ & $4.53^{b}(0.69-13.98)$ & & & $<0.01$ \\
\hline Bifidobacterium & $0.51^{\mathrm{bc}}(0-2.74)$ & $8.22^{\mathrm{a}}(0-19.04)$ & $1.57^{\mathrm{b}}(0-5.46)$ & $0^{d}(0-1.72)$ & $15.65^{\mathrm{a}}(2.61-17.8)$ & $0.58^{\mathrm{cd}}(0-4.75)$ & 0.01 & & $<0.01$ \\
\hline Coriobacteriaceae:g_ & $\mathrm{O}^{\mathrm{b}}(0-0.82)$ & $0^{\mathrm{b}}(0-0)$ & $1.31^{a}(0-5.57)$ & $0^{b}(0-0)$ & $0^{b}(0-0)$ & $0^{\mathrm{b}}(0-8.58)$ & $<0.01$ & $<0.01$ & $<0.01$ \\
\hline Adlercreutzia & $0.19^{\mathrm{ab}}(0-0.55)$ & $0^{c}(0-0)$ & $0^{\mathrm{b}}(0-0.73)$ & $0^{\mathrm{bc}}(0-0.55)$ & $0^{c}(0-0)$ & $0.36^{a}(0-1.29)$ & 0.03 & & $<0.01$ \\
\hline Collinsella & $1.06^{\mathrm{a}, \beta}(0.4-2.62)$ & $0.51^{\mathrm{b}, \beta}(0-2.38)$ & $0.58^{a, \beta}(0-6.86)$ & $1.79^{\mathrm{a}, \alpha}(0.47-6.75)$ & $1.34^{\mathrm{b}, \alpha}(0-2.9)$ & $3.25^{\mathrm{a}, \alpha}(0.33-6.81)$ & & 0.01 & 0.04 \\
\hline Slackia & $0^{b c}(0-0.13)$ & $0^{c}(0-0)$ & $0^{c}(0-0)$ & $0^{\mathrm{b}}(0-0.3)$ & $0^{c}(0-0)$ & $0.24^{\mathrm{a}}(0-0.4)$ & 0.01 & 0.03 & 0.01 \\
\hline Bacteroidetes & $18.63^{\mathrm{a}, \alpha}(6.36-30.48)$ & $0.22^{\mathrm{c}, \alpha}(0-10.9)$ & $20.18^{\mathrm{b}, \alpha}(0.97-31.88)$ & $19.11^{\mathrm{a}, \beta}(0.43-29.42)$ & $\mathrm{O}^{\mathrm{c}, \beta}(0-0.18)$ & $3.41^{\mathrm{b}, \beta}(0-9.27)$ & & 0.01 & $<0.01$ \\
\hline Bacteroides & $5.11^{a}(0.61-12.81)$ & $0^{c}(0-6.54)$ & $6.8^{\mathrm{b}}(0-13.1)$ & $6.12^{\mathrm{a}}(0-17.99)$ & $0^{c}(0-0.18)$ & $1.65^{\mathrm{b}}(0-6.67)$ & & & $<0.01$ \\
\hline Prevotella & $0.27^{\mathrm{a}, \alpha}(0-1.34)$ & $0^{\mathrm{c}, \alpha}(0-0)$ & $0^{b, \alpha}(0-3.39)$ & $0.22^{\mathrm{a}, \beta}(0-0.64)$ & $0^{c, \beta}(0-0.1)$ & $\mathrm{O}^{\mathrm{b}, \beta}(0-1.21)$ & & $<0.01$ & $<0.01$ \\
\hline S24_7:g_ & $1.5^{\mathrm{ab}}(0-9.73)$ & $0^{d}(0-0.67)$ & $8.39^{\mathrm{a}}(0-15.2)$ & $0.16^{\mathrm{bc}}(0-8.82)$ & $0^{d}(0-0)$ & $\mathrm{ocd}^{\mathrm{cd}}(0-7.05)$ & 0.02 & $<0.01$ & $<0.01$ \\
\hline [Paraprevotellaceae]:g_ & $0.27^{a}(0-1.34)$ & $\mathrm{O}^{\mathrm{b}}(0-0)$ & $0^{\mathrm{a}}(0-3.39)$ & $0.22^{a}(0-0.64)$ & $\mathrm{O}^{\mathrm{b}}(0-0.1)$ & $\mathrm{O}^{\mathrm{a}}(0-1.21)$ & & & $<0.01$ \\
\hline [Prevotella] & $6.73^{\mathrm{a}, \alpha}(1.97-13.7)$ & $0^{\mathrm{c}, \alpha}(0-4.4)$ & $1.67^{\mathrm{b}, \alpha}(0-7.27)$ & $2.67^{\mathrm{a}, \beta}(0.12-12.22)$ & $0^{\mathrm{c}, \beta}(0-0)$ & $\mathrm{O}^{\mathrm{b}, \beta}(0-2.94)$ & & $<0.01$ & $<0.01$ \\
\hline Firmicutes & $64.62^{b}(46.15-81.31)$ & $88.53^{\mathrm{a}}(71.55-94.76)$ & $66.8^{\mathrm{b}}(49.2-87.16)$ & $57.75^{\mathrm{b}}(44.63-92.6)$ & $82.77^{\mathrm{a}}(79.81-96.84)$ & $79.11^{\mathrm{a}}(70.93-94.58)$ & 0.04 & & $<0.01$ \\
\hline Enterococcus & $0^{\mathrm{b}}(0-0)$ & $0^{\mathrm{a}}(0-5.17)$ & $\mathrm{O}^{\mathrm{b}}(0-0)$ & $\mathrm{O}^{\mathrm{b}}(0-0)$ & $1.71^{\mathrm{a}}(0-3.75)$ & $\mathrm{O}^{\mathrm{b}}(0-0)$ & & & $<0.01$ \\
\hline Lactobacillus & $0.48^{b}(0-11.24)$ & $32.7^{a}(0-54.52)$ & $0.4^{b}(0-1.65)$ & $0.5^{\mathrm{b}}(0-23.85)$ & $25.96^{a}(18.31-50.35)$ & $0.41^{\mathrm{b}}(0-7.56)$ & & & $<0.01$ \\
\hline Streptococcus & $0.19^{\mathrm{c}}(0-1.48)$ & $26.89^{\mathrm{a}}(0-41.4)$ & $0.4^{\mathrm{b}}(0-6.88)$ & $0^{\mathrm{C}}(0-4.83)$ & $18.42^{\mathrm{a}}(3.59-36.64)$ & $5.31^{\mathrm{b}}(0-17.5)$ & & & $<0.01$ \\
\hline Turicibacter & $5.9^{\mathrm{ab}}(1.38-13.21)$ & $\mathrm{O}^{\mathrm{d}}(0-0.62)$ & $2.18^{\mathrm{C}}(0-8.86)$ & $3.25^{\text {bc }}(0-19.05)$ & $0^{d}(0-0.27)$ & $9.43^{a}(1.16-25.61)$ & $<0.01$ & & $<0.01$ \\
\hline Clostridiaceae:_ & $7.4^{\mathrm{ab}}(5.66-14.95)$ & $0.4^{\mathrm{C}}(0-0.98)$ & $2.73^{\mathrm{b}}(0.91-17.52)$ & $9.68^{\mathrm{a}}(0.58-18.58)$ & $\mathrm{O}^{\mathrm{C}}(0-0.4)$ & $11.99^{a}(5.97-16.48)$ & 0.01 & & $<0.01$ \\
\hline Clostridiaceae:g_ & $0.29^{a}(0-1.91)$ & $\mathrm{O}^{\mathrm{b}}(0-5.08)$ & $0.64^{\mathrm{a}}(0-2.78)$ & $1.49^{\mathrm{a}}(0-3.02)$ & $0^{\mathrm{b}}(0-1.07)$ & $1.63^{\mathrm{a}}(0-3.04)$ & & & 0.01 \\
\hline Clostridium & $0^{C}(0-0.14)$ & $0^{c}(0-0.7)$ & $0^{\mathrm{bc}}(0-2.08)$ & $0^{\mathrm{ab}}(0-3.61)$ & $0^{c}(0-0)$ & $0.57^{\mathrm{a}}(0-10.36)$ & 0.05 & & $<0.01$ \\
\hline Lachnospiraceae:_ & $3.78^{\mathrm{bc}}(1-5.6)$ & $5.65^{\mathrm{a}}(2.1-13.67)$ & $1.68^{\mathrm{C}}(0-9.23)$ & $3.2^{\mathrm{bc}}(1.29-8.72)$ & $4.57^{\mathrm{ab}}(1.07-16.09)$ & $5.88^{\mathrm{a}}(3.42-9.01)$ & 0.01 & & \\
\hline Blautia & $3.47^{\beta}(0.54-8.09)$ & $2.93^{\beta}(0-16.39)$ & $3.12^{\beta}(0-15.33)$ & $9.36^{\alpha}(0-18.48)$ & $3.98^{\alpha}(0.5-11.03)$ & $10.31^{\alpha}(2.03-15.09)$ & & 0.03 & \\
\hline [Ruminococcus] & $2.68^{\mathrm{b}}(0-4.8)$ & $3.5^{\mathrm{ab}}(0-14.16)$ & $5.07^{\mathrm{a}}(0-13.45)$ & $5.08^{\mathrm{a}}(2.16-8.94)$ & $2.47^{\mathrm{ab}}(0-19.82)$ & $4.67^{\mathrm{a}}(2.26-8.26)$ & 0.05 & & \\
\hline Peptococcus & $0.53^{\mathrm{a}}(0-1.28)$ & $0^{\mathrm{b}}(0-0.11)$ & $0^{\mathrm{b}}(0-1.39)$ & $0.38^{a}(0-2.33)$ & $\mathrm{O}^{\mathrm{b}}(0-0)$ & $0.92^{\mathrm{a}}(0-2.38)$ & 0.01 & & $<0.01$ \\
\hline Peptostreptococcus & $0^{b, \alpha}(0-0.28)$ & $0^{\mathrm{b}, \alpha}(0-0.3)$ & $0.96^{\mathrm{a}, \alpha}(0-6.82)$ & $0^{b, \beta}(0-0)$ & $0^{\mathrm{b}, \beta}(0-0)$ & $0^{a, \beta}(0-7.59)$ & & 0.02 & $<0.01$ \\
\hline Ruminococcaceae:g_ & $1.34^{\mathrm{a}, \alpha}(0-2.74)$ & $0^{b, \alpha}(0-0.87)$ & $0.57^{\mathrm{a}, \alpha}(0.22-1.27)$ & $0.23^{a, \beta}(0-1.83)$ & $\mathrm{O}^{\mathrm{b}, \beta}(0-0)$ & $0.27^{\mathrm{a}, \beta}(0-2.02)$ & & 0.03 & $<0.01$ \\
\hline Faecalibacterium & $3.12^{\mathrm{a}}(0.53-8.38)$ & $\mathrm{O}^{\mathrm{C}}(0-1.32)$ & $\mathrm{O}^{\mathrm{b}}(0-2.18)$ & $2.44^{a}(0-10.02)$ & $\mathrm{O}^{\mathrm{C}}(0-0.11)$ & $0.94^{b}(0-5.1)$ & & & $<0.01$ \\
\hline Megamonus & $1.05^{\mathrm{a}}(0-3.72)$ & $0^{c}(0-0)$ & $0^{\mathrm{b}}(0-1.96)$ & $0.76^{a}(0-4.64)$ & $\mathrm{O}^{\mathrm{C}}(0-0.24)$ & $0.37^{b}(0-1.64)$ & & & $<0.01$ \\
\hline Phascolarctobacterium & $1.51^{\mathrm{a}}(0.4-2.75)$ & $0^{c}(0-0.59)$ & $0.07^{\mathrm{b}}(0-1.21)$ & $0.64^{\mathrm{a}}(0-2.69)$ & $0^{c}(0-0)$ & $0^{\mathrm{b}}(0-1.01)$ & & & $<0.01$ \\
\hline Erysipelotrichaceae:g_ & $0.48^{\mathrm{ab}}(0.11-1.79)$ & $\mathrm{o}^{\mathrm{cd}}(0-1.39)$ & $0.18^{\mathrm{bc}}(0-3.06)$ & $1.02^{\mathrm{a}}(0-3.11)$ & $0^{d}(0-0)$ & $1.21^{\mathrm{a}}(0-4.22)$ & 0.01 & & $<0.01$ \\
\hline Allobaculum & $19.85^{\mathrm{b}}(0.56-51.64)$ & $5.39^{\mathrm{cd}}(1.88-21.72)$ & $39.42^{\mathrm{a}}(4.07-49.3)$ & $4.2^{\mathrm{d}}(0-29.34)$ & $11.2^{\mathrm{bc}}(0-22.04)$ & $2.09^{d}(1.12-40.59)$ & $<0.01$ & 0.02 & \\
\hline Catenibacterium & $0.67^{\mathrm{a}, \beta}(0-8.1)$ & $\mathrm{O}^{\mathrm{b}, \beta}(0-4.84)$ & $0^{a, \beta}(0-11.62)$ & $6.17^{\mathrm{a}, \alpha}(0-12.65)$ & $0.23^{b, \alpha}(0-2.32)$ & $4.48^{\mathrm{a}, \alpha}(0-16.53)$ & & 0.01 & $<0.01$ \\
\hline [Eubacterium] & $0.89^{a}(0.4-5.16)$ & $0.07^{b}(0-10.31)$ & $0^{\mathrm{b}}(0-9.22)$ & $4.88^{\mathrm{a}}(0.5-6.45)$ & $0^{\mathrm{b}}(0-0.27)$ & $4.93^{\mathrm{a}}(0-10.86)$ & $<0.01$ & 0.03 & $<0.01$ \\
\hline Fusobacteria & $12^{\mathrm{a}}(6.39-18.91)$ & $0^{c}(0-14.44)$ & $5.57^{\mathrm{b}}(1.38-11.9)$ & $12^{\mathrm{a}}(0-27.67)$ & $\mathrm{O}^{\mathrm{C}}(0-0.3)$ & $9.26^{\mathrm{b}}(0-17.19)$ & & & $<0.01$ \\
\hline Fusobacterium & $12^{\mathrm{a}}(6.39-18.91)$ & $\mathrm{O}^{\mathrm{C}}(0-14.44)$ & $5.57^{\mathrm{b}}(1.38-11.9)$ & $11.96^{a}(0-21.48)$ & $0^{c}(0-0.3)$ & $9.26^{\mathrm{b}}(0-17.19)$ & & & $<0.01$ \\
\hline Proteobacteria & $2.2^{\mathrm{a}}(0.63-4.59)$ & $0.76^{\mathrm{b}}(0-4.51)$ & $1.61^{\mathrm{ab}}(0-11.4)$ & $2.89^{a}(0.4-7.67)$ & $0.17^{\mathrm{b}}(0-6.85)$ & $1.68^{\mathrm{ab}}(0-3.72)$ & & & 0.01 \\
\hline Succinivibrionaceae:g_ & $0.66^{a}(0.25-1.96)$ & $0^{b}(0-0)$ & $\mathrm{O}^{\mathrm{b}}(0-1)$ & $0.82^{\mathrm{a}}(0-4.06)$ & $0^{b}(0-0)$ & $0.69^{a}(0-2.78)$ & 0.04 & & $<0.01$ \\
\hline
\end{tabular}

P-values were adjusted based on the Benjamini and Hochberg False discovery rate (fdr). Relative abundances that do not share a common superscript letter differed significantly (fdr-adjusted $P<0.05)$ based on post-hoc analysis. 
ASVs, 11 of which had neither treatment group nor group-bytime effects.

With regard to quantitative PCR results, group-by-time interactions and time effects were identified for the dysbiosis index and abundances for several bacteria (Figure 3). Significant group-by-time interactions were identified for Faecalibacterium $(P=0.02)$, Turicibacter $(P=0.002)$, Streptococcus $(P=0.048)$, Blautia $(P=0.042)$, and $C$. hiranonis $(P<0.001)$. Main effect
A

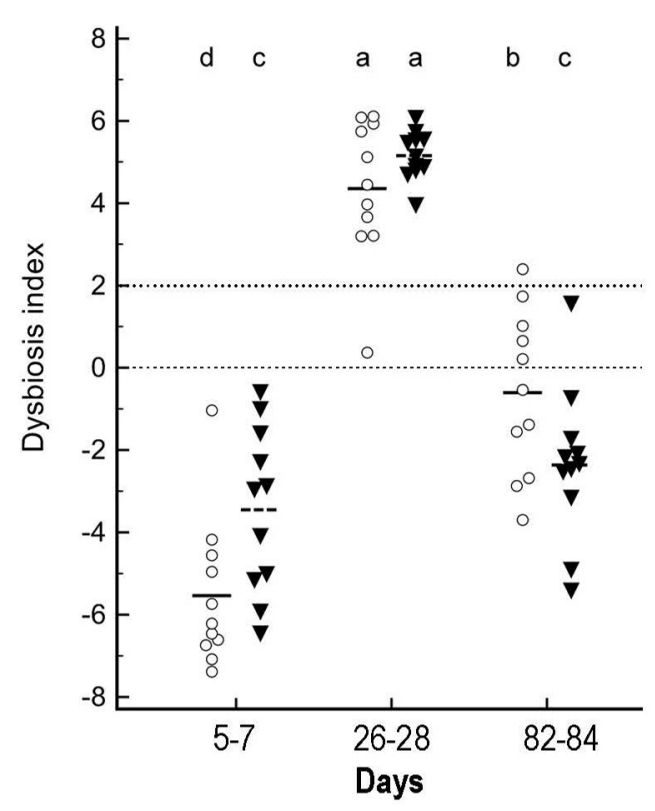

C

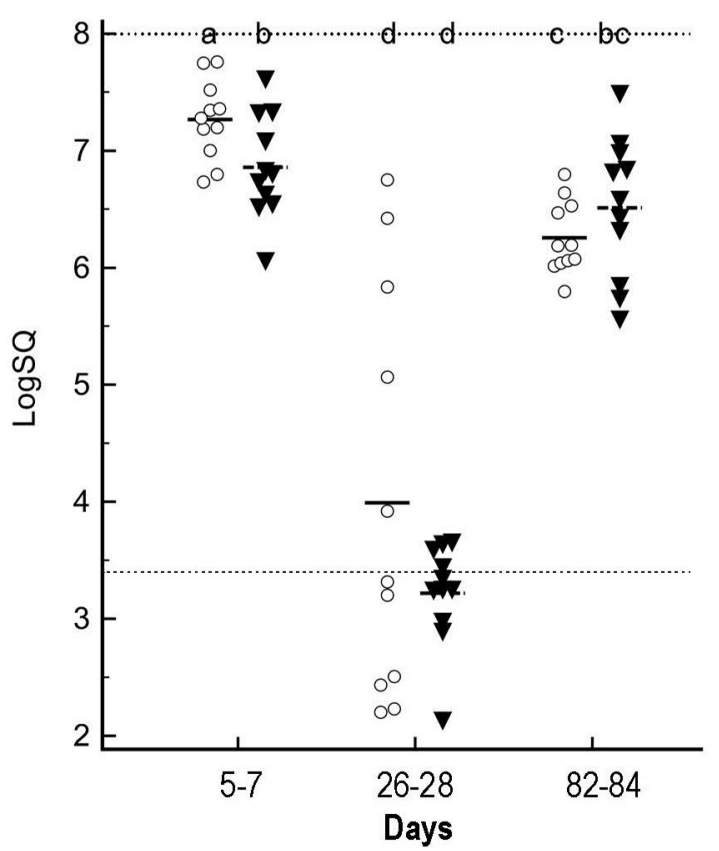

B

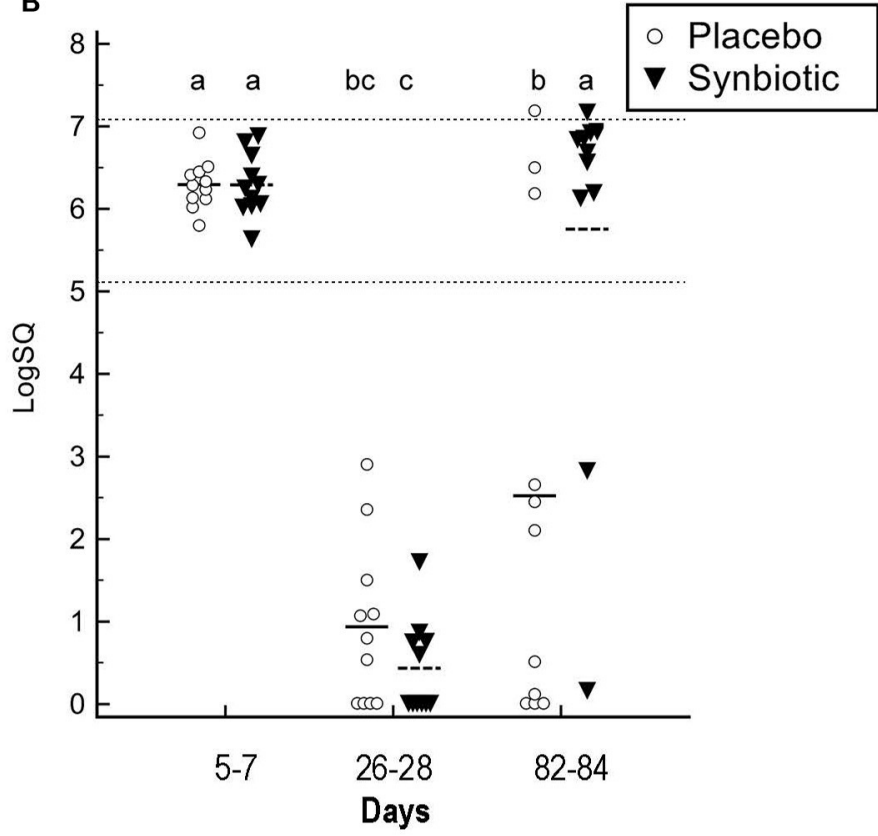

D

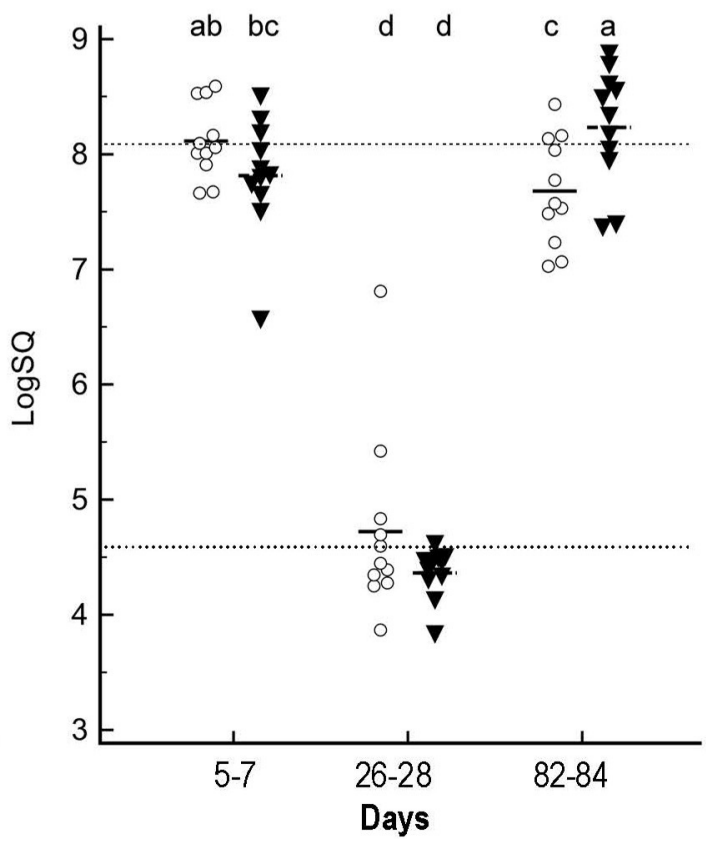

FIGURE 3 | Fecal dysbiosis index results and selected bacterial abundances determined by qPCR. (A) Dysbiosis index. (B) C. hiranonis. (C) Faecalibacterium. (D) Turicibacter. Medians and individual values are presented for dogs in the placebo (open circles) and synbiotic (black triangles) treatment groups. Dotted lines indicate the reference interval. For the dysbiosis index, values $<0$ indicate normobiosis, between 0 and 2 are equivocal, and $>2$ indicate dysbiosis. Significance was set as $P<0.05$. Abundances that do not share a letter differed significantly based on post-hoc analysis. 
differences over time were observed for E. coli, Fusobacterium, and total bacteria $(P<0.001$, for each). Dysbiosis index values differed over time based on treatment received $(P=0.002)$. Post-hoc tests revealed that the dysbiosis index was significantly higher on days 26-28 when compared to days 5-7 for both treatment groups $(P<0.001$, for each), with return to baseline values at days $82-84$ in dogs administered the synbiotic but not the placebo. This difference primarily was due to return of C. hiranonis, as well as Faecalibacterium and Turicibacter, abundances to baseline values for dogs in the synbiotic group

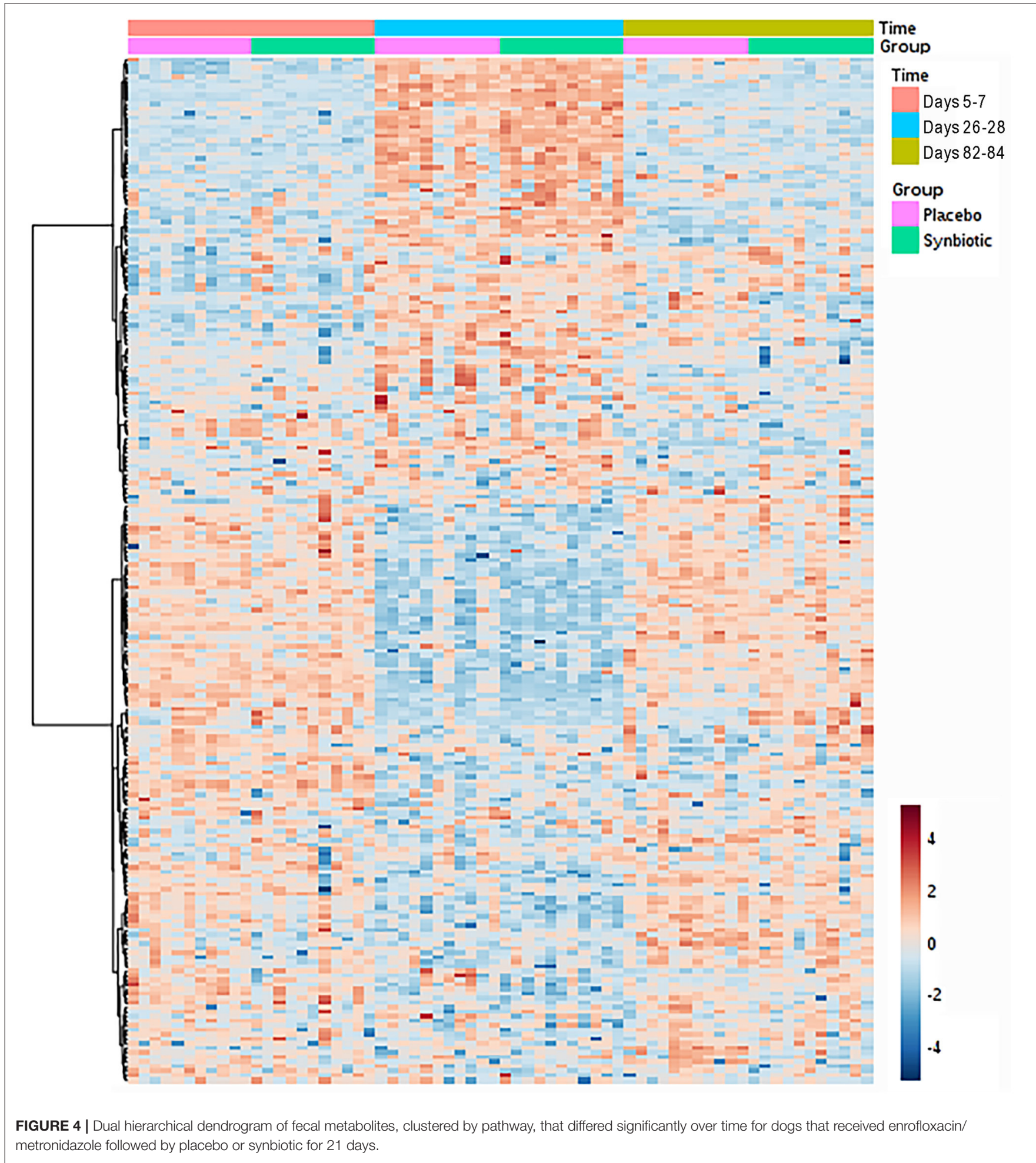


(Figure 3). Total abundance of bacteria at days 82-84 did not differ from baseline for either group.

\section{Fecal Metabolomics}

Based on comparison of spectral analysis results to database compounds, 227 compounds were identified. Profiles for 196 metabolites differed significantly (fdr-adjusted $P<0.05$ ) over the course of the study (Figure 4, Table 3, Supplementary Table 2). Treatment group-by-time interactions were present for 28 metabolites, whereas concurrent group and time effects were identified for 20 metabolites. One hundred fifty-one metabolites had significant temporal changes alone or in combination with group-by-time interactions.

A variety of significant temporal patterns of change were identified. Profiles for 73 metabolites differed from baseline on days $26-28$ with return to baseline values at day $82-84$, whereas recovery to baseline values was incomplete for an additional 45 metabolites. Twenty metabolites had profiles that differed from baseline on days 26-28 without significant change thereafter. Profiles for 17 metabolites were significantly different at days 82-84 compared to baseline and days 26-28, with no difference between profiles for the other two time points. Finally, 16 metabolites had significant derangements compared to baseline on days 26-28 with overcorrection past baseline values on days 82-84. More complex patterns of change were noted for dogs with treatment group-by-time interactions.

Significant group-by-time, group, and time effects were identified for 35 metabolites related to short-chain fatty acid (SCFA), bile acid, tryptophan, and sphingolipid metabolism (Table 4). Significant associations were also present for profiles related to cinnaminic acid and benzoic acid metabolites. Finally, group-by-time and time effects were noted for profiles for fucose and ethanolamine, respectively.

Based on the PCA plot (Figure 5), samples for both treatment groups clustered together at baseline with separate, but overlapping, clustering on days 26-28. Samples from days 82-84 from dogs in the synbiotic group clustered closely with baseline samples for both treatment groups, whereas samples from dogs in the placebo group had little overlap with baseline samples. Visually, metabolites associated with loading axis 1 had changes related to antibiotic administration. These included 4hydroxycinnaminic acid, short chain fatty acids [including 3(3-hydroxyphenyl)propionic, 2-aminobutyric, and phenylacetic acid], tryptophan metabolites (indole-3-acetate and kynurenic acid), and bile acids (lithocholic, deoxycholic, and cholic acid). Metabolites aligned with loading axis 2 included cellobiose, energy substrates (particularly fucose and ethanolamine), and additional short-chain fatty acids.

\section{DISCUSSION}

Oral administration of enrofloxacin with metronidazole causes hyporexia, vomiting, and diarrhea in 41,77 , and $100 \%$ of healthy dogs, with partial mitigation of signs in dogs also administered synbiotics (5). Based on results of this study, derangements in the fecal microbiome and metabolome secondary to combination enrofloxacin/metronidazole therapy also are severe. Recovery of the fecal microbiome and metabolome differed significantly between treatment groups after antibiotic discontinuation. Significant group-by-time interactions were noted for numerous ASVs associated with eubiosis; SCFA, bile acid, tryptophan, and sphingolipid metabolites; profiles for antioxidants and antimicrobials; and bacterial energy substrate profiles.

Derangements in the fecal microbiome secondary to antibiotic therapy in dogs and cats previously have been reported for a variety of antibiotics $(3,4,6,7,11,12)$. Alpha diversity metrics, beta diversity, and the dysbiosis index were significantly altered by clindamycin administration to cats, with recovery occurring between 44 and 603 days after antibiotic discontinuation $(4,6)$. Alpha diversity metrics, beta diversity, and the dysbiosis index also were significantly altered in healthy dogs by administration of tylosin for 7 days (12). Alpha diversity metrics and the dysbiosis index returned to baseline values 56 days after antibiotic discontinuation, whereas unweighted beta diversity remained significantly altered. Although the dysbiosis index and total observed species did not differ significantly between baseline and the conclusion of washout in that study, derangements in abundance of C. hiranonis, Faecalibacterium, and Turicibacter persisted. Interestingly, significant effects on the relative abundance of individual ASVs were uncommon-potentially due to use of categorical vs. quantitative statistical analysis.

The impact of metronidazole monotherapy $(12.5-15 \mathrm{mg} / \mathrm{kg}$ $\mathrm{mg} / \mathrm{kg}$ BID $\times 14$ days) on the fecal microbiome and metabolome also has been described $(7,11)$. Alpha and beta diversity were significantly deranged during antibiotic administration in both studies, with complete recovery of alpha diversity 14-28 days after antibiotic discontinuation. Beta diversity, however, remained significantly different from baseline 28 days after antibiotic discontinuation in one of the two studies (7). Abundances of Bifidobacterium and Gammaproteobacteria increased during antibiotics then returned to baseline levels during washout in both studies, whereas Bacteroides decreased during or after antibiotic therapy with variable recovery during washout. The composition of the phylum Firmicutes changed significantly during antibiotic administration in both studies. The abundance of Lactobacillales significantly increased during antibiotic administration, whereas the abundance of beneficial Clostridial species declined during antibiotic administration with recovery thereafter $(7,11)$. In addition to microbiome derangements, diarrhea was noted in one of the two studies (7).

Alpha and beta diversity, as well as the dysbiosis index, were significantly altered during antibiotic administration for both treatment groups in this study. Consistent with prior reports, total bacteria decreased during antibiotic administration with recovery to baseline abundance during washout. However, recovery of alpha diversity metrics was incomplete at the conclusion of the washout period for dogs in both treatment groups. Beta diversity and the dysbiosis index also remained significantly different from baseline for dogs in the placebo group. Derangements were present in this study for a greater number of genera and other ASVs compared to previous reports from dogs and cats $(3,4,6,11,12)$, primarily in the same bacterial families and clusters. The most likely explanation for the greater number of ASVs affected is the 
TABLE 3 | Median (range) peak height of fecal metabolites with significant group-by-time interactions or concurrent group and time effects for dogs that received enrofloxacin/metronidazole followed by placebo or synbiotic for 21 days.

\begin{tabular}{|c|c|c|c|c|c|c|c|c|c|}
\hline & \multicolumn{3}{|c|}{ Placebo } & \multicolumn{3}{|c|}{ Synbiotic } & \multicolumn{3}{|c|}{ fdr $P$-value } \\
\hline & Baseline & Days 26-28 & Days 82-84 & Baseline & Days 26-28 & Days 82-84 & Group* Time & Group & Time \\
\hline 1-deoxyerythritol & $\begin{array}{c}3,943^{\mathrm{a}, \beta} \\
(2,376-6,884)\end{array}$ & $\begin{array}{c}1,759^{\mathrm{c, \beta}} \\
(1,115-3,795)\end{array}$ & $\begin{array}{c}2,573^{\mathrm{b}, \beta} \\
(1,251-10,686)\end{array}$ & $\begin{array}{c}5,810^{\mathrm{a}, \alpha} \\
(3,564-10,619)\end{array}$ & $\begin{array}{c}3,286^{c, \alpha} \\
(1,783-4,037)\end{array}$ & $\begin{array}{c}3,514^{b, \alpha} \\
(2,194-5,834)\end{array}$ & & $<0.01$ & $<0.01$ \\
\hline 2-hydroxyglutaric acid & $617^{\mathrm{bc}}(351-1,769)$ & $752^{b}(269-8,379)$ & $961^{b}(242-3,611)$ & $497^{\text {cd }}(264-881)$ & $2,999^{\mathrm{a}}(734-10,872)$ & $336^{d}(185-733)$ & $<0.01$ & & $<0.01$ \\
\hline 2-monoolein & $\begin{array}{c}13,913^{a} \\
(9,341-31,985)\end{array}$ & $\begin{array}{c}4,732^{\mathrm{c}} \\
(2,417-9,397)\end{array}$ & $\begin{array}{c}10,091^{\mathrm{b}} \\
(4,217-15,122)\end{array}$ & $\begin{array}{c}10,370^{\mathrm{b}} \\
(996-23,452)\end{array}$ & $\begin{array}{c}4,657^{\mathrm{c}} \\
(2,260-9,157)\end{array}$ & $\begin{array}{c}14,264^{\mathrm{ab}} \\
(5,223-17,870)\end{array}$ & 0.02 & & $<0.01$ \\
\hline 3-phenyllactic acid & $1,589^{d}(621-6,453)$ & $\begin{array}{c}20,424^{\mathrm{a}} \\
(13,289-58,071)\end{array}$ & $\begin{array}{c}12,004^{\mathrm{b}} \\
(2,943-26,814)\end{array}$ & $\begin{array}{c}2,804^{\text {cd }} \\
(1,659-7,204)\end{array}$ & $\begin{array}{c}35,635^{a} \\
(25,628-54,631)\end{array}$ & $\begin{array}{c}5,172^{\mathrm{c}} \\
(1,561-10,187)\end{array}$ & 0.02 & & $<0.01$ \\
\hline Allantoic acid & $574^{a b}(346-9,428)$ & $363^{\mathrm{ab}}(57-5,302)$ & $372^{\mathrm{b}}(98-1,417)$ & $479^{b}(262-7,659)$ & $525^{\mathrm{b}}(71-8,130)$ & $1,060^{\mathrm{a}}(237-8,365)$ & 0.045 & & \\
\hline Behenic acid & $\begin{array}{c}17,039^{\mathrm{a}} \\
(10,554-27,314)\end{array}$ & $\begin{array}{c}12,039^{b} \\
(5,630-33,623)\end{array}$ & $\begin{array}{c}8,485^{\mathrm{c}} \\
(6,598-16,857)\end{array}$ & $\begin{array}{c}18,397^{a} \\
(5,337-37,951)\end{array}$ & $\begin{array}{c}8,169^{\circ} \\
(4,824-16,919)\end{array}$ & $\begin{array}{c}9,831^{\mathrm{bc}} \\
(3,974-17,712)\end{array}$ & 0.045 & & $<0.01$ \\
\hline Butane-2,3-diol NIST & $\begin{array}{c}3,568^{\mathrm{c}} \\
(2,699-7,200)\end{array}$ & $\begin{array}{c}66,839 \mathrm{ab} \\
(1,848-177,389)\end{array}$ & $\begin{array}{c}14,081^{\mathrm{ab}} \\
(1,978-946,157)\end{array}$ & $\begin{array}{c}5,832^{\mathrm{bc}} \\
(2,181-74,843)\end{array}$ & $\begin{array}{c}73,860^{\mathrm{a}} \\
(4,516-207,742)\end{array}$ & $3,401^{\mathrm{c}}(831-20,343)$ & $<0.01$ & & $<0.01$ \\
\hline Cholesterol & $\begin{array}{c}149,365^{a, \alpha} \\
(103,904-195,152)\end{array}$ & $\begin{array}{c}75,299^{\mathrm{c}, \alpha} \\
(32,531-146,078)\end{array}$ & $\begin{array}{c}83,947^{\mathrm{b}, \alpha} \\
(55,654-152,213)\end{array}$ & $\begin{array}{c}100,350^{a, \beta} \\
(75,261-321,230)\end{array}$ & $\begin{array}{c}52,181^{\mathrm{c}, \beta} \\
(37,103-73,759)\end{array}$ & $\begin{array}{c}87,172^{\mathrm{b}, \beta} \\
(51,653-178,799)\end{array}$ & & 0.04 & $<0.01$ \\
\hline Daidzein & $473^{\mathrm{b}, \beta}(251-5,277)$ & $\begin{array}{c}9,026^{\mathrm{a}, \beta} \\
(2,351-11,387)\end{array}$ & $368^{\mathrm{b}, \beta}(217-9,333)$ & $921^{\mathrm{b}, \alpha}(448-15,926)$ & $\begin{array}{c}8,394^{a, \alpha} \\
(1,659-15,777)\end{array}$ & $\begin{array}{c}5,369^{\mathrm{b}, \alpha} \\
(397-15,651)\end{array}$ & & 0.01 & $<0.01$ \\
\hline Deoxycholic acid & $\begin{array}{c}420,927^{\mathrm{a}}(287,558- \\
1,547,882)\end{array}$ & $\begin{array}{c}2,962^{\text {cd }} \\
(1,273-413,873)\end{array}$ & $\begin{array}{c}149,001^{\mathrm{C}} \\
(872-267,037)\end{array}$ & $\begin{array}{c}225,249^{b} \\
(110,916-674,640)\end{array}$ & $2,284^{d}(733-6,615)$ & $\begin{array}{c}255,829^{b} \\
(3,037-756,630)\end{array}$ & 0.02 & & $<0.01$ \\
\hline D-erythro-sphingosine & $\begin{array}{c}6,805^{\mathrm{a}} \\
(2,526-29,549)\end{array}$ & $\begin{array}{c}3,756^{\mathrm{bc}} \\
(975-18,571)\end{array}$ & $2,036^{\mathrm{cd}}(915-5,138)$ & $\begin{array}{c}4,890^{\mathrm{ab}} \\
(955-11,023)\end{array}$ & $1,622^{d}(672-9,162)$ & $\begin{array}{c}4,518^{\mathrm{ab}} \\
(3,092-14,801)\end{array}$ & 0.01 & & $<0.01$ \\
\hline Docosahexaenoic acid & $\begin{array}{c}17,299^{\mathrm{a}, \alpha} \\
(13,147-48,544)\end{array}$ & $\begin{array}{c}5,222^{\mathrm{c}, \alpha} \\
(988-12,968)\end{array}$ & $\begin{array}{c}16,575^{\mathrm{b}, \alpha} \\
(7,393-31,581)\end{array}$ & $\begin{array}{c}11,549^{a, \beta} \\
(6,307-34,081)\end{array}$ & $\begin{array}{c}1,527^{\mathrm{c}, \beta} \\
(1,433-5,486)\end{array}$ & $\begin{array}{c}10,141^{\mathrm{b}, \beta} \\
(2,105-18,520)\end{array}$ & & 0.02 & $<0.01$ \\
\hline Erythritol & $\begin{array}{c}4,250^{\mathrm{b}, \beta} \\
(2,176-21,769)\end{array}$ & $\begin{array}{c}13,219^{\mathrm{a}, \beta} \\
(1,480-31,839)\end{array}$ & $913^{\mathrm{C}, \beta}(413-11,712)$ & $\begin{array}{c}4,025^{\mathrm{b}, \alpha} \\
(907-19,062)\end{array}$ & $\begin{array}{c}24,525^{\mathrm{a}, \alpha} \\
(20,722-46,236)\end{array}$ & $\begin{array}{c}2,312^{\mathrm{c}, \alpha} \\
(852-10,345)\end{array}$ & & 0.01 & $<0.01$ \\
\hline Ferulic acid & $1,192^{\mathrm{bc}}(652-1,736)$ & $1,920^{\mathrm{ab}}(408-4,344)$ & $563^{d}(137-1,194)$ & $861^{c d}(405-1,233)$ & $\begin{array}{c}2,122^{\mathrm{a}} \\
(1,300-3,853)\end{array}$ & $964^{\text {bc }}(522-2,479)$ & 0.03 & & $<0.01$ \\
\hline Fucose & $\begin{array}{c}179,811^{\mathrm{a}} \\
(41,782-233,563)\end{array}$ & $\begin{array}{c}137,082^{\mathrm{a}} \\
(3,849-837,808)\end{array}$ & $\begin{array}{c}13,332^{\mathrm{c}} \\
(8,185-320,277)\end{array}$ & $\begin{array}{c}137,859^{a b} \\
(50,951-233,808)\end{array}$ & $\begin{array}{c}68,870^{\mathrm{bc}} \\
(1,751-169,428)\end{array}$ & $\begin{array}{c}120,553^{\mathrm{ab}} \\
(17,516-264,172)\end{array}$ & 0.01 & & \\
\hline Galactinol & $695^{\mathrm{b}, \beta}(534-1,667)$ & $981^{a, \beta}(823-2,975)$ & $522^{\mathrm{c}, \beta}(303-1,023)$ & $\begin{array}{c}1,050^{\mathrm{b}, \alpha} \\
(518-2,174)\end{array}$ & $\begin{array}{c}1,893^{\mathrm{a}, \alpha} \\
(1,219-3,985)\end{array}$ & $500^{\mathrm{c}, \alpha}(279-1,951)$ & & 0.047 & $<0.01$ \\
\hline Galactose & $\begin{array}{c}163,560^{\mathrm{a}} \\
(56,259-288,199)\end{array}$ & $\begin{array}{c}39,870^{\mathrm{bc}} \\
(19,078-237,206)\end{array}$ & $\begin{array}{c}24,910^{\text {cd }} \\
(8,818-308,074)\end{array}$ & $\begin{array}{c}102,098^{\mathrm{ab}} \\
(46,025-202,159)\end{array}$ & $\begin{array}{c}27,749^{d} \\
(7,301-69,499)\end{array}$ & $\begin{array}{c}121,530^{\mathrm{ab}} \\
(28,291-493,825)\end{array}$ & 0.03 & & $<0.01$ \\
\hline Glutamic acid & $\begin{array}{c}121,446^{\mathrm{b}} \\
(95,863-179,885)\end{array}$ & $\begin{array}{c}250,811^{\mathrm{a}} \\
(116,078-408,091)\end{array}$ & $\begin{array}{c}132,799^{\mathrm{b}} \\
(60,403-435,886)\end{array}$ & $\begin{array}{c}135,038^{b} \\
(95,213-274,191)\end{array}$ & $\begin{array}{c}275,893^{\mathrm{a}} \\
(162,620-470,665)\end{array}$ & $\begin{array}{c}80,460^{\circ} \\
(30,579-124,299)\end{array}$ & 0.01 & & $<0.01$ \\
\hline Glutaric acid & $896^{a, \beta}(426-1,641)$ & $768^{\mathrm{a}, \beta}(318-3,303)$ & $470^{\mathrm{b}, \beta}(303-1,245)$ & $1,141^{\mathrm{a}, \alpha}(554-2,124)$ & $1,343^{\mathrm{a}, \alpha}(530-8,514)$ & $573^{b, \alpha}(519-1,390)$ & & 0.03 & $<0.01$ \\
\hline $\begin{array}{l}\text { Glycerol-alpha- } \\
\text { phosphate }\end{array}$ & $1,332^{\mathrm{C}}(130-2,070)$ & $2,743^{\mathrm{b}}(774-4,096)$ & $1,420^{\mathrm{bc}}(774-2,365)$ & $1,055^{\mathrm{C}}(95-2,587)$ & $\begin{array}{c}3,960^{a} \\
(2,865-5,321)\end{array}$ & $1,224^{\mathrm{c}}(253-1,980)$ & 0.03 & & $<0.01$ \\
\hline
\end{tabular}


TABLE 3 | Continued

\begin{tabular}{|c|c|c|c|c|c|c|c|c|c|}
\hline & \multicolumn{3}{|c|}{ Placebo } & \multicolumn{3}{|c|}{ Synbiotic } & \multicolumn{3}{|c|}{ fdr $P$-value } \\
\hline & Baseline & Days 26-28 & Days 82-84 & Baseline & Days 26-28 & Days 82-84 & Group* Time & Group & Time \\
\hline Hexadecylglycerol NIST & $\begin{array}{c}6,021^{\mathrm{a}, \alpha} \\
(4,332-11,689)\end{array}$ & $2,783^{\mathrm{c}, \alpha}(620-3,860)$ & $\begin{array}{c}4,273^{\mathrm{b}, \alpha} \\
(1,897-5,447)\end{array}$ & $\begin{array}{c}3,592^{\mathrm{a}, \beta} \\
(2,727-12,350)\end{array}$ & $1,632^{\mathrm{c}, \beta}(678-3,580)$ & $\begin{array}{c}2,959^{\mathrm{b}, \beta} \\
(1,246-5,882)\end{array}$ & & 0.02 & $<0.01$ \\
\hline Indole-3-propionic acid & $\begin{array}{c}14,629^{a, \alpha} \\
(8,342-41,807)\end{array}$ & $\begin{array}{c}6,359^{\mathrm{b}, \alpha} \\
(273-11,067)\end{array}$ & $\begin{array}{c}21,609^{a, \alpha} \\
(11,397-213,321)\end{array}$ & $\begin{array}{c}9,929^{a, \beta} \\
(6,433-39,621)\end{array}$ & $\begin{array}{c}4,103^{\mathrm{b}, \beta} \\
(122-8,132)\end{array}$ & $\begin{array}{c}9,006^{a, \beta} \\
(5,149-261,311)\end{array}$ & & 0.01 & $<0.01$ \\
\hline Inosine & $843^{\mathrm{a}}(191-18,392)$ & $178^{\mathrm{C}}(103-4,221)$ & $437^{b}(134-6,505)$ & $2,812^{\mathrm{a}}(475-16,194)$ & $145^{\circ}(96-253)$ & $6,424^{a}(417-12,002)$ & 0.01 & & $<0.01$ \\
\hline Isoleucine & $\begin{array}{c}218,417^{c} \\
(144,351-405,106)\end{array}$ & $\begin{array}{c}382,705^{\mathrm{ab}} \\
(274,560-647,973)\end{array}$ & $\begin{array}{c}442,249^{a} \\
(270,033-602,789)\end{array}$ & $\begin{array}{c}295,250^{\mathrm{ab}} \\
(214,178-674,190)\end{array}$ & $\begin{array}{c}322,186^{\mathrm{b}} \\
(183,901-691,552)\end{array}$ & $\begin{array}{c}420,279^{\mathrm{a}} \\
(250,849-929,432)\end{array}$ & 0.02 & & $<0.01$ \\
\hline Linoleic acid & $\begin{array}{c}31,003^{\mathrm{a}, \alpha} \\
(19,842-58,595)\end{array}$ & $\begin{array}{c}6,812^{\mathrm{b}, \alpha} \\
(2,085-17,820)\end{array}$ & $\begin{array}{c}25,853^{\mathrm{a}, \alpha} \\
(12,932-47,171)\end{array}$ & $\begin{array}{c}14,912^{\mathrm{a}, \beta} \\
(8,022-36,173)\end{array}$ & $\begin{array}{c}4,846^{\mathrm{b}, \beta} \\
(1,882-8,382)\end{array}$ & $\begin{array}{c}25,814^{\mathrm{a}, \mathrm{\beta}} \\
(11,785-33,998)\end{array}$ & & 0.02 & $<0.01$ \\
\hline Lysine & $\begin{array}{c}91,686^{a, \alpha} \\
(59,571-204,631)\end{array}$ & $\begin{array}{c}37,443^{b, \alpha} \\
(4,793-129,197)\end{array}$ & $\begin{array}{c}195,379^{a, \alpha} \\
(4,376-244,884)\end{array}$ & $\begin{array}{c}88,520^{\mathrm{a}, \beta} \\
(35,630-172,381)\end{array}$ & $\begin{array}{c}37,148^{\mathrm{b}, \beta} \\
(19,483-63,945)\end{array}$ & $\begin{array}{c}75,462^{\mathrm{a}, \mathrm{\beta}} \\
(8,834-135,588)\end{array}$ & & 0.04 & $<0.01$ \\
\hline Maltose & $\begin{array}{c}3,321^{\mathrm{ab}} \\
(1,174-15,494)\end{array}$ & $2,055^{b}(443-12,081)$ & $5,510^{\mathrm{a}}(990-13,210)$ & $\begin{array}{c}2,142^{\mathrm{b}} \\
(1,296-12,555)\end{array}$ & $\begin{array}{c}4,835^{a} \\
(1,370-26,980)\end{array}$ & $\begin{array}{c}2,483^{b} \\
(1,114-6,542)\end{array}$ & 0.02 & & \\
\hline Methionine sulfoxide & $\begin{array}{c}25,019^{\mathrm{b}, \alpha} \\
(16,164-32,096)\end{array}$ & $\begin{array}{c}15,187^{\mathrm{c}, \alpha} \\
(3,893-40,207)\end{array}$ & $\begin{array}{c}43,425^{a, \alpha} \\
(24,804-61,200)\end{array}$ & $\begin{array}{c}27,844^{\mathrm{b}, \beta} \\
(9,120-42,782)\end{array}$ & $\begin{array}{c}10,510^{\mathrm{c}, \beta} \\
(5,714-17,172)\end{array}$ & $\begin{array}{c}29,577^{\mathrm{a}, \beta} \\
(7,316-54,293)\end{array}$ & & 0.02 & $<0.01$ \\
\hline $\mathrm{N}$-acetylglutamate & $611^{a}(452-1,813)$ & $545^{\mathrm{a}}(306-1,779)$ & $856^{a}(251-3,533)$ & $585^{a}(418-2,128)$ & $570^{\mathrm{a}}(269-2,982)$ & $253^{\mathrm{b}}(189-1,387)$ & 0.02 & & \\
\hline Ornithine & $\begin{array}{c}39,943^{b, \alpha} \\
(7,429-60,274)\end{array}$ & $\begin{array}{c}32,926^{b, \alpha} \\
(3,931-67,775)\end{array}$ & $\begin{array}{c}106,782^{a, \alpha} \\
(37,067-161,661)\end{array}$ & $\begin{array}{c}41,914^{\mathrm{b}, \beta} \\
(14,623-55,508)\end{array}$ & $\begin{array}{c}31,069^{b, \beta} \\
(13,064-44,642)\end{array}$ & $\begin{array}{c}38,525^{a, \beta} \\
(14,556-67,033)\end{array}$ & & $<0.01$ & 0.01 \\
\hline Oxoproline & $\begin{array}{c}61,545^{\mathrm{bc}} \\
(54,924-112,476)\end{array}$ & $\begin{array}{c}340,035^{\mathrm{a}} \\
(82,079-490,827)\end{array}$ & $\begin{array}{c}91,480^{\mathrm{b}} \\
(48,067-308,646)\end{array}$ & $\begin{array}{c}75,373^{\text {bc }} \\
(48,333-228,173)\end{array}$ & $\begin{array}{c}390,081^{\mathrm{a}} \\
(316,439-630,055)\end{array}$ & $\begin{array}{c}50,243^{\mathrm{c}} \\
(38,250-137,407)\end{array}$ & 0.03 & & $<0.01$ \\
\hline Phenylacetic acid & $\begin{array}{c}4,975^{b} \\
(3,312-24,386)\end{array}$ & $1,324^{\mathrm{c}}(446-6,138)$ & $\begin{array}{c}9,494^{\mathrm{ab}} \\
(3,106-20,887)\end{array}$ & $\begin{array}{c}11,517^{\mathrm{a}} \\
(3,607-50,106)\end{array}$ & $908^{\mathrm{C}}(626-3,941)$ & $\begin{array}{c}9,363^{\mathrm{ab}} \\
(2,780-23,596)\end{array}$ & 0.04 & & $<0.01$ \\
\hline $\begin{array}{l}\text { P-hydroxylphenyllactic } \\
\text { acid }\end{array}$ & $552^{\mathrm{C}}(305-1,332)$ & $2,802^{\mathrm{a}}(990-7,942)$ & $2,157^{\mathrm{b}}(747-5,019)$ & $645^{\mathrm{C}}(236-3,049)$ & $\begin{array}{c}5,232^{\mathrm{a}} \\
(1,761-8,091)\end{array}$ & $856^{c}(402-1,859)$ & 0.01 & & $<0.01$ \\
\hline Phytosphingosine & $\begin{array}{c}6,552^{\mathrm{a}} \\
(4,474-14,350)\end{array}$ & $\begin{array}{c}3,373^{\mathrm{bc}} \\
(1,053-36,357)\end{array}$ & $\begin{array}{c}5,011^{\mathrm{bc}} \\
(2,568-5,546)\end{array}$ & $\begin{array}{c}4,056^{c} \\
(1,714-8,857)\end{array}$ & $\begin{array}{c}2,686^{d} \\
(1,639-6,759)\end{array}$ & $\begin{array}{c}5,229^{\mathrm{ab}} \\
(3,312-11,865)\end{array}$ & 0.02 & & $<0.01$ \\
\hline Resorcinol & $1,122^{\mathrm{a}}(263-1,440)$ & $86^{c}(60-144)$ & $298^{b}(127-1,160)$ & $417^{b}(147-2,294)$ & $89^{c}(67-107)$ & $543^{b}(121-1,962)$ & 0.03 & & $<0.01$ \\
\hline Ribonic acid & $1,295^{\text {bc }}(841-2,265)$ & $\begin{array}{c}2,623^{\mathrm{a}} \\
(1,690-6,569)\end{array}$ & $1,252^{\mathrm{b}}(659-2,982)$ & $1,182^{\mathrm{bc}}(412-1,987)$ & $\begin{array}{c}3,303^{\mathrm{a}} \\
(2,363-4,531)\end{array}$ & $961^{\mathrm{C}}(509-1,395)$ & 0.03 & & $<0.01$ \\
\hline Sinapinic acid & $793^{\mathrm{b}, \beta}(195-1,046)$ & $1,872^{\mathrm{a}, \beta}(358-4,872)$ & $593^{\mathrm{b}, \beta}(459-776)$ & $776^{\mathrm{b}, \alpha}(561-1,769)$ & $\begin{array}{c}2,750^{\mathrm{a}, \alpha} \\
(1,008-5,776)\end{array}$ & $782^{\mathrm{b}, \alpha}(531-1,458)$ & & 0.02 & $<0.01$ \\
\hline Sorbitol & $\begin{array}{c}7,753^{\mathrm{a}, \beta} \\
(1,676-58,914)\end{array}$ & $\begin{array}{c}5,530^{a, \beta} \\
(1,395-51,870)\end{array}$ & $\begin{array}{c}1,853^{\mathrm{b}, \beta} \\
(1,049-2,261)\end{array}$ & $\begin{array}{c}5,343^{\mathrm{a}, \alpha} \\
(2,302-44,389)\end{array}$ & $\begin{array}{c}9,181^{\mathrm{a}, \alpha} \\
(3,005-54,449)\end{array}$ & $\begin{array}{c}3,107^{\mathrm{b}, \alpha} \\
(656-7,939)\end{array}$ & & 0.02 & $<0.01$ \\
\hline Thymidine & $\begin{array}{c}9,507^{\mathrm{a}, \alpha} \\
(4,687-14,694)\end{array}$ & $\begin{array}{c}2,350^{\mathrm{c}, \alpha} \\
(1,095-7,641)\end{array}$ & $\begin{array}{c}7,075^{\mathrm{b}, \alpha} \\
(1,920-11,952)\end{array}$ & $\begin{array}{c}7,150^{\mathrm{a}, \beta} \\
(4,227-11,471)\end{array}$ & $1,826^{\mathrm{C}, \beta}(823-3,809)$ & $\begin{array}{c}4,999^{b, \beta} \\
(1,774-12,346)\end{array}$ & & 0.046 & $<0.01$ \\
\hline Thymine & $\begin{array}{c}46,343^{b} \\
(27,601-68,823)\end{array}$ & $\begin{array}{c}8,471^{d} \\
(3,608-26,848)\end{array}$ & $\begin{array}{c}30,637^{\mathrm{c}} \\
(17,424-50,012)\end{array}$ & $\begin{array}{c}68,273^{\mathrm{a}} \\
(43,452-77,166)\end{array}$ & $\begin{array}{c}6,774^{d} \\
(4,152-15,770)\end{array}$ & $\begin{array}{c}45,188^{\mathrm{bc}} \\
(24,105-75,344)\end{array}$ & 0.04 & & $<0.01$ \\
\hline Tocopherol acetate & $\begin{array}{c}2,491^{a, \beta} \\
(1,105-7,290)\end{array}$ & $\begin{array}{c}1,728^{\mathrm{b}, \beta} \\
(379-3,256)\end{array}$ & $\begin{array}{c}1,764^{\mathrm{b}, \beta} \\
(817-5,111)\end{array}$ & $\begin{array}{c}5,993^{\mathrm{a}, \alpha} \\
(1,472-8,182)\end{array}$ & $\begin{array}{c}2,087^{\mathrm{b}, \alpha} \\
(934-3,937)\end{array}$ & $\begin{array}{c}3,653^{\mathrm{b}, \alpha} \\
(760-10,497)\end{array}$ & & 0.03 & $<0.01$ \\
\hline
\end{tabular}




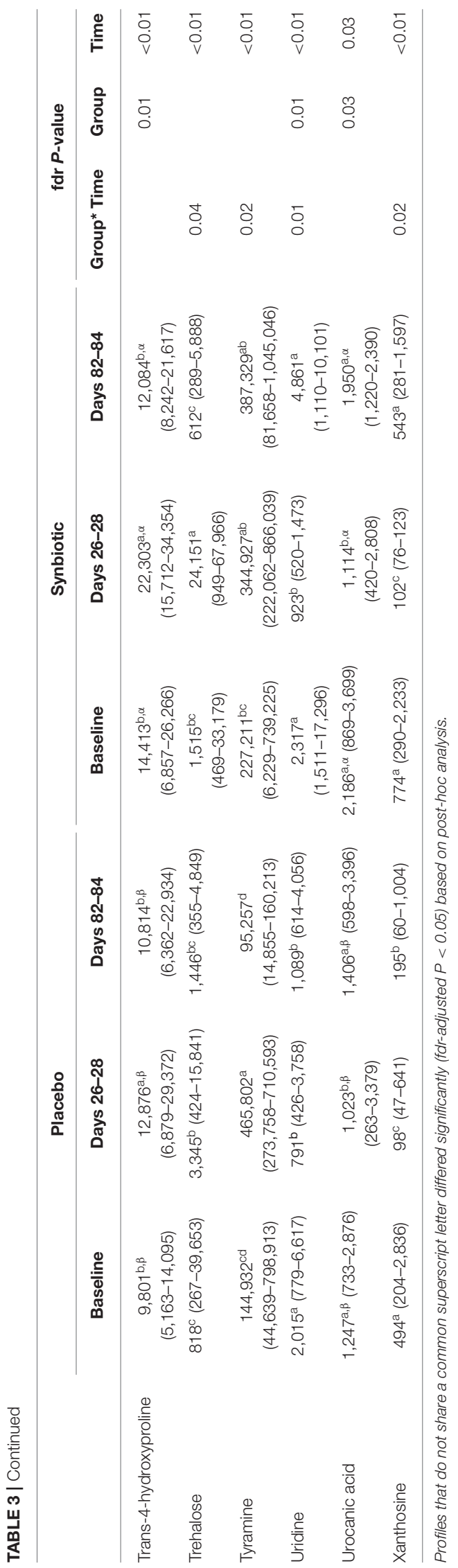

use of a broader spectrum antibiotic combination. The relative abundances of Bifidobacterium, Lactobacillus, Streptococcus, and Lachnospiraceae increased during antibiotic administration, whereas decreases were identified for the relative abundances of Adlercreutzia, Collinsella, Bacteroides, Prevotella, and members of the Clostridium clusters IV and XIV. Persistent or delayed derangements in relative abundance of 16 genera were identified at the conclusion of washout for dogs in the placebo group. Quantitative PCR demonstrated persistent decreases in abundances of C. hiranonis, Faecalibacterium, and Turicibacter.

Based on results of prior studies, relative abundances for some ASVs might return to baseline abundance in the weeks following antibiotic discontinuation only to decline or overshoot past baseline values over a longer time frame $(4,6,12)$. When considering genera with abundances that differed significantly in two studies of clindamycin administration in cats, recovery to baseline values at the terminal sampling time point (44 or 603 days after antibiotic discontinuation, respectively) was concordant for only four of 18 genera. Genera with persistent or delayed derangements in abundance included Bifidobacterium, Adlercreutzia, Bacteroides, Oscillospira, Ruminococcus, Megasphaera, and numerous members of the Clostridium clusters IV and XIV. Because this study included only one post-antibiotic sampling time point, it was not possible to determine whether ASVs might undergo similar longer-term alterations in dogs. However, for genera with discordant patterns of recovery among reports, results of this study generally matched those of the shorter-term cat study.

Changes in the fecal microbiome in this study also are consistent with results seen in dogs with naturally-occurring acute and chronic enteropathies $(9,13-16)$. Similarities in results among studies could reflect relatively recent exposure to antibiotics in studies of naturally-occurring enteropathies or a shared underlying pathologic response. It also is possible that adult-onset enteropathies are the clinical manifestation of dysbiosis induced by historical antibiotic exposure alone or in combination with historical gastrointestinal insult (17). Differentiation among these possibilities will require collection of more robust antibiotic histories with inclusion of exposure times and types as covariates in large-scale analyses. Pending those data, it is prudent to avoid unnecessary antibiotic usage and mitigate antibiotic-induced dysbiosis when possible. Synbiotic administration impacted the recovery of the fecal microbiome after antibiotic administration in this study. Beta diversity and the dysbiosis index returned to baseline levels only for dogs administered the synbiotic combination as did abundances for $C$. hiranonis, Faecalibacterium, and Turicibacter. Finally, significant group-by-time interactions were noted for 28 ASVs in this study. These changes occurred in spite of discontinuation of the synbiotic combination at the same time as antibiotics, instead of 4-6 weeks thereafter as is often recommended in people.

Antibiotics have been found to markedly derange the fecal metabolome of dogs (7), but the ameliorative effects of synbiotics on antibiotic-induced derangements previously have not been described. Profiles for $86 \%$ of identified metabolites were significantly altered by antibiotic therapy, alone or in 
TABLE 4 | Median (range) peak height of metabolites of known biological importance with profiles that significantly differed over the course of the study in feces collected at the conclusion of baseline (days 5-7), antibiotic administration (days 26-28), and a 56-day washout (days 82-84) from 22 healthy dogs, 11 per group, ${ }^{+}$that received enrofloxacin (10 mg/kg qd) and metronidazole (12.5 mg/kg BID), followed $1 \mathrm{~h}$ later by placebo or a synbiotic combination (BID) PO for 21 days.

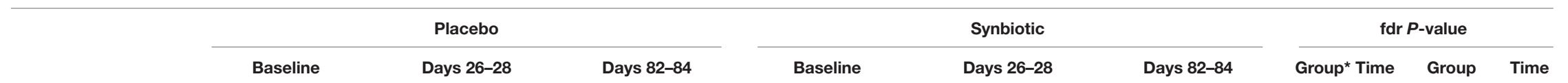

\section{Short chain fatty acid metabolites}

2,4-diaminobutyric acid

2-aminobutyric acid

2-deoxytetronic acid

2-hydroxybutanoic acid

3-(3-

hydroxyphenyl)propionic acid

3-(4-

hydroxyphenyl)propionic

acid

3-hydroxybutyric acid

3-phenyllactic acid

4-aminobutyric acid

4-hydroxybutyric acid

4-hydroxyphenylacetic

Butane-2,3-diol NIST

Butyrolactam NIST

Lactic acid

Phenylacetic acid

P-hydroxylphenyllactic acid $5,551^{\mathrm{a}}$ $(1,401-9,021)$ $90,013^{b}$

$1,223^{\mathrm{C}}(417-12,349)$ $90,013^{\mathrm{b}}$ 4,042 $(1,569-22,356)$ $5,994^{\mathrm{b}}$ $(3,221-29,404)$ $4,623^{\mathrm{a}}$ $(3,406-5,736)$ $7,459^{2}$ (3,499-36,854)

$261,529^{a}$

$$
(8,474-99,922)
$$

$$
\begin{gathered}
7,184^{a} \\
(3,027-10,079)
\end{gathered}
$$

$1,589^{d}(621-6,453)$

$6,834^{a}$ $(5,180-11,170)$

$$
1,814^{b}
$$

$(1,170-10,221)$

$42,535^{\mathrm{a}}$

$(27,466-79,397)$

$3,568^{\circ}$

$(2,699-7,200)$

$6,568^{\mathrm{a}}$

(4,141-17,913)

$580^{\mathrm{b}}(187-136,848)$

$4,975^{\mathrm{b}}$

$(3,312-24,386)$

$552^{\mathrm{C}}(305-1,332)$ $2,712^{\mathrm{b}}(237-11,586)$

$20,424^{a}$

(13,289-58,071)

$1,610^{\mathrm{b}}(718-10,973)$

$3,859^{\mathrm{a}}$
$(2,692-7,318)$

$19,423^{b}$

(2,564-41,632)

66,839 ab

$(1,848-177,389)$

$2,789^{\circ}$

(1,935-5,064)

$864,555^{a}$

(184-1,701,564)

$1,324^{\mathrm{C}}(446-6,138)$

$2,802^{\mathrm{a}}(990-7,942)$

$2,661^{\mathrm{b}}$
$(1,021-3,656)$
$130,033^{\mathrm{a}}$
$(44,028-344,232)$
$2,324^{\mathrm{a}}$
$(1,540-8,108)$
$24,725^{\mathrm{a}}$
$(9,275-51,409)$
$4,689^{\mathrm{a}}$
$(1,896-6,488)$
$32,758^{\mathrm{a}}$
$(845-55,405)$
$127,896^{\mathrm{b}}$

(1,944-250,573)

$269,044^{a}$

$(45,812-687,935)$

$5,124^{\mathrm{a}}$

$(1,888-7,023)$

$122,729^{b}$

(36,089-212,264)

$5,048^{a}$

$(1,250-49,806)$

$7,342^{\mathrm{b}}$

$(3,971-113,729)$

$4,375^{\mathrm{a}}$

$(2,677-21,425)$

$7,710^{a}$

(3,770-20,700)

$129,710^{a}$

(3,303-569,367)

\section{$121,925^{b}$ \\ (28,869-268,775)}

$$
\begin{gathered}
7,454^{\mathrm{a}} \\
366-13,042)
\end{gathered}
$$

$12,004^{\mathrm{b}}$

(2,943-26,814)

$2,702^{\mathrm{b}}(190-5,965)$

$3,519^{b}$
$(1,627-6,761)$

$61,252^{\mathrm{a}}$

(21,157-105,898)

$14,081^{\mathrm{ab}}$

(1,978-946,157)

$4,346^{\mathrm{b}}$

$(2,453-5,128)$

$36,973^{b}$

(136-169,063)

9,494 ${ }^{\mathrm{ab}}$

(3,106-20,887)

$2,157^{\mathrm{b}}(747-5,019)$

$10,391^{\mathrm{a}}$

$(3,067-50,349)$

$2,804^{\mathrm{cd}}$

$(1,659-7,204)$

$5,889^{a}$

(2,841-20,586)

$1,843^{\mathrm{b}}$

$(1,206-4,719)$

$41,639^{a}$

$(19,711-123,186)$

$5,832^{\mathrm{bc}}$

$(2,181-74,843)$

$5,853^{\mathrm{a}}$

$(4,049-11,196)$

$524^{\mathrm{b}}(174-79,629)$

$11,517^{\mathrm{a}}$

$(3,607-50,106)$

$645^{\mathrm{C}}(236-3,049)$

\section{$1,042^{\mathrm{c}}(523-2,201) \quad 2,845^{\mathrm{b}}(903-5,453)$}

$8,978^{\circ}$

$(5,239-62,097)$

$892^{\mathrm{b}}(526-1,978)$

$9,169^{b}$

(1,147-37,955)

$965^{\mathrm{b}}(597-9,128)$

$3,380^{\mathrm{b}}(460-12,971)$

$1,527^{\circ}(924-4,003)$

$$
\text { (924-4,003) }
$$

$20,974^{\mathrm{C}}$

$(6,288-35,824)$

$1,618^{\mathrm{b}}(443-7,224)$

$35,635^{a}$

$(25,628-54,631)$

$3,310^{\circ}$

(1,330-10,461)

$4,089^{a}$

$(2,598-6,759)$

$16,726^{\mathrm{b}}$

(160-24,795)

$73,860^{\mathrm{a}}$

(4,516-207,742)

$3,469^{\circ}$

$(1,678-5,100)$

$1,322,605$

$(117-2,202,609)$

908 $(626-3,941)$

$5,232^{\mathrm{a}}$ (1,761-8,091) $136,646^{a}$

$(85,394-326,247)$

$3,829^{a}$

(1,140-14,386)

$16,023^{\mathrm{a}}$

(6,796-46,386)

$4,067^{\mathrm{a}}$

$(1,883-8,770)$

$2,883^{a}$

$(2,204-78,482)$

$142,548^{\mathrm{b}}$

(14,129-321,723)

$155,582^{\mathrm{a}}$

$(86,037-894,720)$

$4,380^{\mathrm{a}}$

$(1,754-46,165)$

$5,172^{\circ}$

$(1,561-10,187)$

$3,585^{\mathrm{b}}$

$(1,658-6,878)$

$1,972^{\mathrm{b}}$

$(1,213-6,025)$

$34,960^{\mathrm{a}}$

(18,054-104,601)

$3,401^{\mathrm{c}}(831-20,343)$

$<0.01$

$<0.01$

$<0.01$

0.01

$$
3,629^{b}
$$

(2,463-8,860)

$17,542^{\mathrm{b}}$

(172-125,633)

$9,363^{\text {ab }}$

(2,780-23,596)

$856^{\mathrm{C}}(402-1,859)$

0.01 
TABLE 4 | Continued

\begin{tabular}{|c|c|c|c|c|c|c|c|c|c|}
\hline & \multicolumn{3}{|c|}{ Placebo } & \multicolumn{3}{|c|}{ Synbiotic } & \multicolumn{3}{|c|}{ fdr $P$-value } \\
\hline & Baseline & Days 26-28 & Days 82-84 & Baseline & Days 26-28 & Days 82-84 & Group* Time & Group & Time \\
\hline Propane-1,3-diol NIST & $\begin{array}{c}6,582^{\mathrm{b}} \\
(4,250-10,253)\end{array}$ & $\begin{array}{c}9,521^{\mathrm{a}} \\
(2,735-17,768)\end{array}$ & $\begin{array}{c}5,215^{\mathrm{b}} \\
(2,976-7,953)\end{array}$ & $\begin{array}{c}4,907^{\mathrm{b}} \\
(1,197-11,000)\end{array}$ & $\begin{array}{c}10,327^{a} \\
(3,009-15,544)\end{array}$ & $4,317^{b}(531-7,219)$ & & & 0.01 \\
\hline \multicolumn{10}{|l|}{ Bile acid metabolites } \\
\hline Cholesterol & $\begin{array}{c}149,365^{a, a} \\
(103,904-195,152)\end{array}$ & $\begin{array}{c}75,299^{\mathrm{c}, a} \\
(32,531-146,078)\end{array}$ & $\begin{array}{c}83,947^{\mathrm{b}, \mathrm{a}} \\
(55,654-152,213)\end{array}$ & $\begin{array}{c}100,350^{a, b} \\
(75,261-321,230)\end{array}$ & $\begin{array}{c}52,181^{\mathrm{c}, \mathrm{b}} \\
(37,103-73,759)\end{array}$ & $\begin{array}{c}87,172^{\mathrm{b}, \mathrm{b}} \\
(51,653-178,799)\end{array}$ & & 0.04 & $<0.01$ \\
\hline Cholic acid & $\begin{array}{c}2,933^{\mathrm{c}} \\
(1,456-13,399)\end{array}$ & $\begin{array}{c}62,504^{\mathrm{a}} \\
(1,494-318,640)\end{array}$ & $\begin{array}{c}9,197^{b} \\
(1,883-71,273)\end{array}$ & $\begin{array}{c}2,849^{c} \\
(1,221-13,634)\end{array}$ & $\begin{array}{c}110,785^{\mathrm{a}} \\
(43,650-229,826)\end{array}$ & $\begin{array}{c}6,631^{b} \\
(1,267-95,346)\end{array}$ & & & $<0.01$ \\
\hline Deoxycholic acid & $\begin{array}{c}420,927^{\mathrm{a}}(287,558- \\
1,547,882)\end{array}$ & $\begin{array}{c}2,962^{\text {cd }} \\
(1,273-413,873)\end{array}$ & $\begin{array}{c}149,001^{\mathrm{c}} \\
(872-267,037)\end{array}$ & $\begin{array}{c}225,249^{\mathrm{b}} \\
(110,916-674,640)\end{array}$ & $2,284^{d}(733-6,615)$ & $\begin{array}{c}255,829^{\mathrm{b}} \\
(3,037-756,630)\end{array}$ & 0.02 & & $<0.01$ \\
\hline Dihydrocholesterol & $\begin{array}{c}1,960^{\mathrm{a}} \\
(1,360-2,384)\end{array}$ & $870^{C}(630-1,538)$ & $1,634^{\mathrm{b}}(923-2,355)$ & $\begin{array}{c}1,659^{\mathrm{a}} \\
(1,017-4,691)\end{array}$ & $774^{\mathrm{C}}(556-1,369)$ & $1,225^{b}(253-2,462)$ & & & $<0.01$ \\
\hline Lithocholic acid & $\begin{array}{c}34,659^{a} \\
(2,094-119,375)\end{array}$ & $647^{c}(401-31,262)$ & $\begin{array}{c}10,073^{\mathrm{b}} \\
(576-24,309)\end{array}$ & $\begin{array}{c}25,565^{\mathrm{a}} \\
(4,269-66,206)\end{array}$ & $496^{\mathrm{C}}(344-810)$ & $\begin{array}{c}18,850^{\mathrm{b}} \\
(639-39,383)\end{array}$ & & & $<0.01$ \\
\hline \multicolumn{10}{|l|}{ Tryptophan metabolites } \\
\hline Indole-3-acetate & $\begin{array}{c}20,743^{\mathrm{a}} \\
(14,077-23,638)\end{array}$ & $\begin{array}{c}3,828^{\mathrm{b}} \\
(1,115-9,503)\end{array}$ & $\begin{array}{c}22,084^{\mathrm{a}} \\
(12,120-48,972)\end{array}$ & $\begin{array}{c}18,542^{a} \\
(10,247-27,294)\end{array}$ & $\begin{array}{c}2,643^{b} \\
(1,675-4,983)\end{array}$ & $\begin{array}{c}18,757^{a} \\
(11,691-99,336)\end{array}$ & & & $<0.01$ \\
\hline Indole-3-lactate & $\begin{array}{c}115,052^{\mathrm{a}} \\
(74,011-172,000)\end{array}$ & $\begin{array}{c}34,761^{\mathrm{c}} \\
(16,259-45,655)\end{array}$ & $\begin{array}{c}48,501^{\mathrm{b}} \\
(19,622-126,079)\end{array}$ & $\begin{array}{c}93,617^{\mathrm{a}} \\
(46,576-150,970)\end{array}$ & $\begin{array}{c}34,770^{\circ} \\
(17,743-46,913)\end{array}$ & $\begin{array}{c}71,855^{\mathrm{b}} \\
(19,782-133,294)\end{array}$ & & & $<0.01$ \\
\hline Indole-3-propionic acid & $\begin{array}{c}14,629^{a, a} \\
(8,342-41,807)\end{array}$ & $\begin{array}{c}6,359^{b, a} \\
(273-11,067)\end{array}$ & $\begin{array}{c}21,609^{\mathrm{a}, \mathrm{a}} \\
(11,397-213,321)\end{array}$ & $\begin{array}{c}9,929^{a, b} \\
(6,433-39,621)\end{array}$ & $\begin{array}{c}4,103^{b, b} \\
(122-8,132)\end{array}$ & $\begin{array}{c}9,006^{\mathrm{a}, \mathrm{b}} \\
(5,149-261,311)\end{array}$ & & 0.01 & $<0.01$ \\
\hline Kynurenic acid & $827^{b}(541-1,176)$ & $6,188^{\mathrm{a}}(388-18,895)$ & $596^{b}(318-1,618)$ & $690^{\mathrm{b}}(397-8,980)$ & $\begin{array}{c}8,283^{a} \\
(3,900-34,883)\end{array}$ & $804^{b}(472-1,830)$ & & & $<0.01$ \\
\hline Tryptophan & $\begin{array}{c}30,456^{\mathrm{b}} \\
(15,983-142,360)\end{array}$ & $\begin{array}{c}99,160^{\mathrm{a}} \\
(21,844-170,273)\end{array}$ & $\begin{array}{c}68,305^{\mathrm{a}} \\
(32,808-138,909)\end{array}$ & $\begin{array}{c}40,964^{\mathrm{b}} \\
(16,338-83,084)\end{array}$ & $\begin{array}{c}87,474^{\mathrm{a}} \\
(51,120-133,855)\end{array}$ & $\begin{array}{c}95,811^{\mathrm{a}} \\
(31,515-284,375)\end{array}$ & & & $<0.01$ \\
\hline \multicolumn{10}{|c|}{ Sphingolipid metabolites } \\
\hline Cellobiose & $\begin{array}{c}15,190^{\mathrm{a}} \\
(5,457-29,788)\end{array}$ & $\begin{array}{c}5,109^{b} \\
(1,738-43,182)\end{array}$ & $\begin{array}{c}5,063^{\mathrm{b}} \\
(2,557-12,603)\end{array}$ & $\begin{array}{c}13,562^{\mathrm{a}} \\
(2,201-25,493)\end{array}$ & $\begin{array}{c}4,212^{\mathrm{b}} \\
(2,808-89,792)\end{array}$ & $\begin{array}{c}10,658^{\mathrm{b}} \\
(1,087-20,781)\end{array}$ & & & 0.01 \\
\hline D-erythro-sphingosine & $\begin{array}{c}6,805^{\mathrm{a}} \\
(2,526-29,549)\end{array}$ & $\begin{array}{c}3,756^{\mathrm{bc}} \\
(975-18,571)\end{array}$ & $2,036^{\mathrm{cd}}(915-5,138)$ & $\begin{array}{c}4,890^{\mathrm{ab}} \\
(955-11,023)\end{array}$ & $1,622^{d}(672-9,162)$ & $\begin{array}{c}4,518^{\mathrm{ab}} \\
(3,092-14,801)\end{array}$ & 0.01 & & $<0.01$ \\
\hline Isopentadecanoic acid & $\begin{array}{c}53,407^{\mathrm{a}} \\
(28,784-91,274)\end{array}$ & $\begin{array}{c}24,171^{\mathrm{c}} \\
(15,867-34,465)\end{array}$ & $\begin{array}{c}29,321^{b} \\
(4,722-51,680)\end{array}$ & $\begin{array}{c}51,526^{\mathrm{a}} \\
(25,488-95,283)\end{array}$ & $\begin{array}{c}16,855^{c} \\
(6,681-316,781)\end{array}$ & $\begin{array}{c}30,903^{b} \\
(16,922-70,276)\end{array}$ & & & $<0.01$ \\
\hline Pentadecanoic acid & $\begin{array}{c}28,576^{a} \\
(14,614-40,686)\end{array}$ & $\begin{array}{c}14,448^{\mathrm{b}} \\
(8,305-31,683)\end{array}$ & $\begin{array}{c}19,097^{\mathrm{b}} \\
(12,240-23,067)\end{array}$ & $\begin{array}{c}25,694^{\mathrm{a}} \\
(17,888-41,885)\end{array}$ & $\begin{array}{c}14,819^{b} \\
(9,078-27,971)\end{array}$ & $\begin{array}{c}17,464^{\mathrm{b}} \\
(3,677-32,186)\end{array}$ & & & $<0.01$ \\
\hline Phytosphingosine & $\begin{array}{c}6,552^{\mathrm{a}} \\
(4,474-14,350)\end{array}$ & $\begin{array}{c}3,373^{\mathrm{bc}} \\
(1,053-36,357)\end{array}$ & $\begin{array}{c}5,011^{\mathrm{bc}} \\
(2,568-5,546)\end{array}$ & $\begin{array}{c}4,056^{c} \\
(1,714-8,857)\end{array}$ & $\begin{array}{c}2,686^{d} \\
(1,639-6,759)\end{array}$ & $\begin{array}{c}5,229^{\mathrm{ab}} \\
(3,312-11,865)\end{array}$ & 0.02 & & $<0.01$ \\
\hline \multicolumn{10}{|c|}{ Antioxidants/antimicrobials } \\
\hline 3-hydroxybenzoic acid & $785^{a}(350-2,503)$ & $190^{\mathrm{b}}(116-262)$ & $548^{\mathrm{a}}(248-2,433)$ & $734^{\mathrm{a}}(352-3,362)$ & $171^{\mathrm{b}}(113-317)$ & $611^{a}(290-8,417)$ & & & $<0.01$ \\
\hline Hexadecylglycerol NIST & $\begin{array}{c}6,021^{\mathrm{a}, \mathrm{a}} \\
(4,332-11,689)\end{array}$ & $2,783^{\mathrm{c}, \mathrm{a}}(620-3,860)$ & $\begin{array}{c}4,273^{\mathrm{b}, \mathrm{a}} \\
(1,897-5,447)\end{array}$ & $\begin{array}{c}3,592^{a, b} \\
(2,727-12,350)\end{array}$ & $\begin{array}{c}1,632^{\mathrm{c}, \mathrm{b}} \\
(678-3,580)\end{array}$ & $\begin{array}{c}2,959^{b, b} \\
(1,246-5,882)\end{array}$ & & 0.02 & $<0.01$ \\
\hline
\end{tabular}




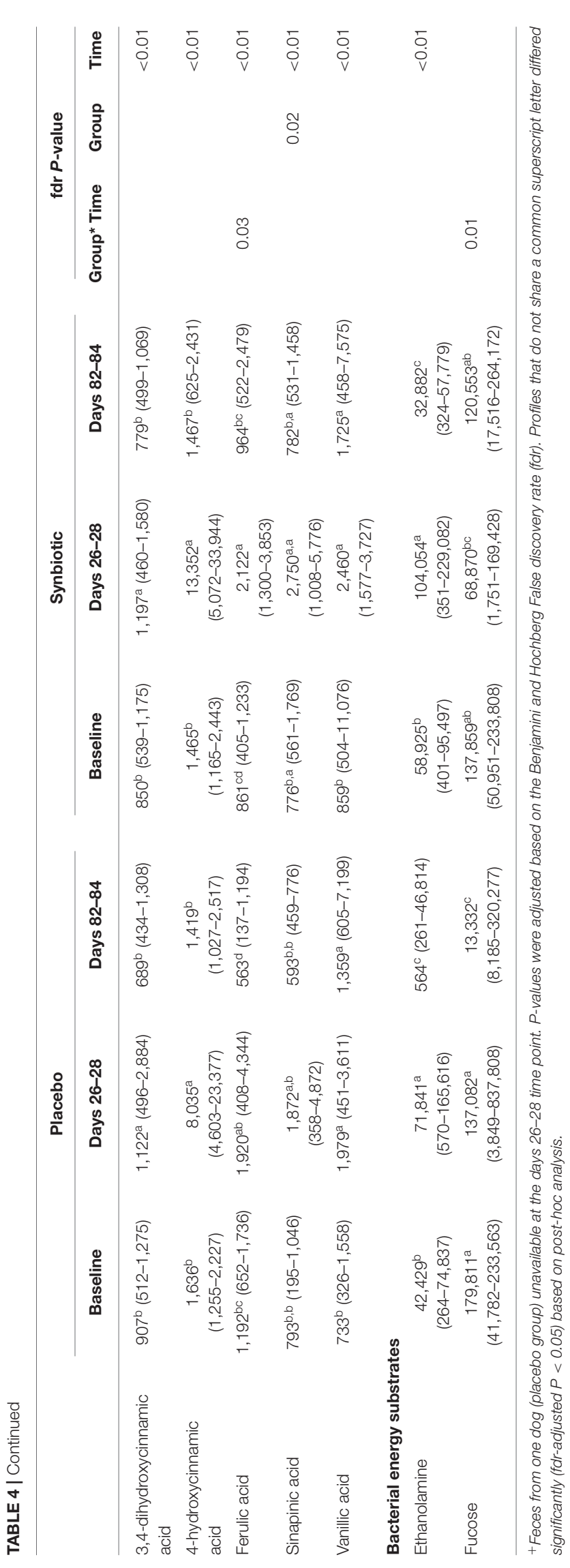

combination with synbiotics. Although the majority of significant associations in this study were temporal, significant groupby-time interactions or concurrent group and time effects were detected for $24 \%$ of metabolites. Furthermore, global fecal metabolite composition significantly differed between treatment groups both during and after antibiotic administration (Figure 5).

Short-chain fatty acids are produced in the large intestine as a result of bacterial carbohydrate fermentation and serve as the preferred energy substrate for colonocytes. However, SCFA also have important roles in increasing $\mathrm{T}$ regulatory cell function, modulating the innate immune system, and increasing intestinal barrier function (18). Significant temporal effects, alone or in combination with group-by-time interactions, were identified for numerous SCFA metabolites. This is not particularly surprising given derangements in abundance of Bifidobacterium, Bacteroides, Prevotella, Lactobacillus, Turicibacter, Megamonas, and members of the Clostridium clusters IV and XIVa (Blautia, C. hiranonis, Ruminococcus, Peptostreptococcus, and Faecalibacterium) -all of which contribute to SCFA production (19). Derangements were persistent at the conclusion of washout for many ASVs and metabolite profiles. Changes were similar to those described in dogs with acute enteropathy both prior to and after metronidazole therapy (16), as well as up to 603 days after clindamycin administration in cats (4).

Bile acid dysmetabolism also was identified during antibiotic administration in this study. Profiles for the secondary bile acids deoxycholic and lithocholic acid significantly decreased during antibiotics, whereas cholic acid profiles increased. Dysmetabolism is believe to reflect a combination of downregulation of apical sodium-dependent bile acid transporters and decreased deconjugation of primary bile acids due to reduced abundances of Eubacterium and Clostridium cluster IV and XIVa species, particularly C. hiranonis in dogs (7, 14, 15). Ramifications of bile acid dysmetabolism can include diarrhea due to osmotic effects, increased intestinal permeability, and altered immune regulation $(14,15,20)$. Bile acid dysmetabolism previously has been described in dogs with both chronic and acute enteropathy, as well as dogs and cats administered antibiotics $(4,6,7,14-16)$. Although changes during antibiotic therapy did not differ between treatment groups in this study, deoxycholic acid profiles normalized after antibiotic discontinuation for the synbiotic group alone with a similar (but non-significant) pattern for lithocholic acid profiles. These results are consistent with prior data showing partial normalization of bile acid profiles in dogs with acute diarrhea treated with fecal transplantation, but not metronidazole, in spite of resolution of clinical signs in both groups (16). In that study, the difference between groups was due to incomplete recovery of C. hiranonis in some dogs in the metronidazole treatment group.

Finally, we identified significant antibiotic-induced derangements in tryptophan, sphingolipid, benzoic acid, and cinnaminic acid metabolism. Tryptophan dysmetabolism was characterized by decreased indole profiles in association with increased tryptophan and kynurenic acid profiles. Both indole products and kynurenic acid increase immune function and epithelial restitution, albeit via different mechanisms 


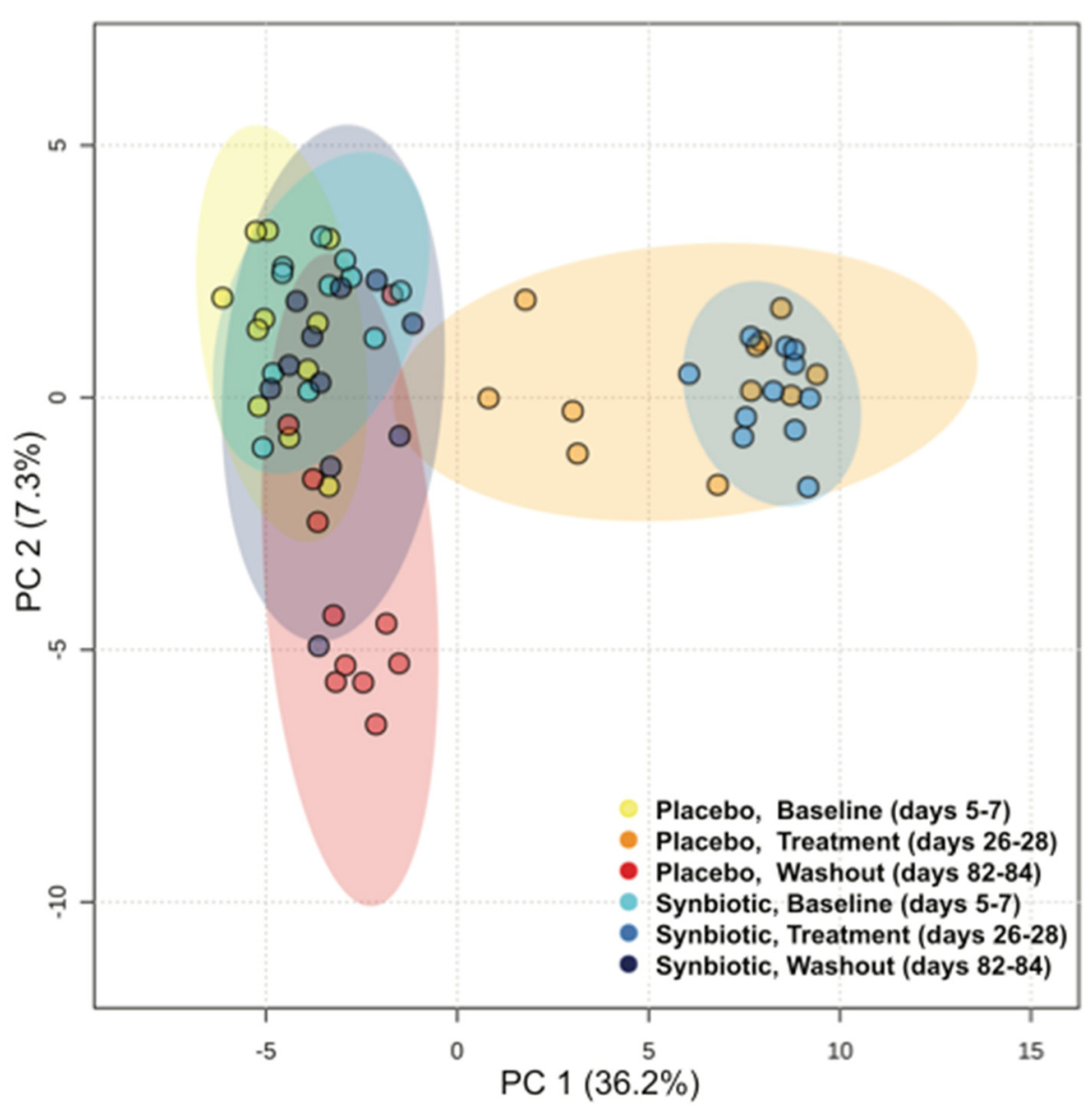

FIGURE 5 | Principal Component Analysis (PCA) of fecal metabolites for dogs that received enrofloxacin/metronidazole followed by placebo or synbiotic for 21 days.

(21). Indole products also increase pathogen resistance via modulation of bacterial virulence factors (21). Although indole-3-acetate and indole-3-proprionic acid profiles returned to baseline after antibiotic discontinuation, recovery was incomplete or absent for indole-3-lactate and tryptophan, suggesting ongoing dysmetabolism. Sphingolipids are important components of the apical cell membrane of intestinal epithelial cells, differentially distributed between villus and crypt cells (22). Dysregulation of sphingolipid production is associated with increased intestinal permeability and a shift from an anti-inflammatory to pro-inflammatory state in mouse models of chronic enteropathy, as well as individuals with Crohn's disease and inflammatory bowel disease (22). Derangements in several sphingolipid metabolites persisted after antibiotic discontinuation for both treatment groups in this study. The exception was D-erythro-sphingosine profiles, which normalized after antibiotic discontinuation for dogs in the synbiotic group. Finally, antibiotic administration significantly affected benzoic and cinnaminic acid profiles, both of which have antimicrobial effects $(23,24)$. Cinnaminic acids also affect management of obesity and diabetes mellitus (24). Recovery after antibiotic discontinuation was mixed for cinnaminic acid metabolites. Persistent tryptophan, sphingolipid, and cinnaminic acid dysmetabolism have been identified over 600 days after clindamycin administration to cats (4), suggesting potentially irreversible effects of antibiotics on metabolic pathways.

One additional finding of this study was significant alterations in ethanolamine and fucose profiles during antibiotic therapy. A key facet of colonization resistance is the ability of commensal bacteria to efficiently process nutrients, such as fucose, to outcompete pathogenic species (25). Inflammation, however, increases exposure of phosphatidylethanolamine from intestinal cell membranes, which is converted to ethanolamine in the lumen (26). Although commensal bacteria have poor ability to metabolize ethanolamine, pathogenic bacteria can alter their metabolism to increase use of ethanolamine, allowing them to rapidly expand and colonize the gut $(26,27)$. The trigger for this metabolic shift in adherent-invasive E. coli is increased propanediol concentrations (28), such as were found in this study. Synbiotic administration was associated with normalization of fucose profiles, whereas fucose profiles decreased after antibiotic discontinuation for the placebo group. Further study is required to determine whether the latter is partially responsible for the incomplete recovery of commensal 
bacteria, such as C. hiranonis, after antibiotic exposure for dogs not administered synbiotics.

The use of healthy research dogs with a uniform diet, husbandry, and environment could be considered a limitation of this study. However, findings were remarkably similar to prior reports of privately-owned healthy dogs administered antibiotics as well as dogs with naturally-occurring gastrointestinal disease $(12,16)$. Although longer than that used in most prior studies (11, 12, 29), follow-up after antibiotic discontinuation was limited and included only one time point. Given previously identified patterns of overshoot or decline after initial normalization of taxa and metabolites $(4,6,12)$, future studies with longer-term follow-up will be necessary to determine the full ramifications of historical antibiotic exposure. Long-term cohort studies of privately-owned animals likely will be required to elucidate the clinical ramifications of persistent antibioticinduced derangements in the microbiome and/or metabolome. Other limitations of this study include lack of targeted metabolite analyses and lack of characterization of archaea, fungi, protists, and viruses, all of which contribute to host-microbiome interactions $(30,31)$.

\section{CONCLUSIONS}

Broad-spectrum antibiotic regimens in dogs are associated with a high incidence of AAGS. Adverse clinical effects are believed to be due to negative effects of antibiotics on the gastrointestinal microbiome, leading to alterations in the metabolome and opportunistic colonization by pathogenic bacteria. Based on results of this study, derangements in the fecal microbiome and metabolome secondary to combination enrofloxacin/metronidazole therapy are profound. Recovery of the fecal microbiome and metabolome composition overall after antibiotic discontinuation was greater for dogs administered synbiotics. Significant group-by-time interactions also were noted for numerous ASVs associated with eubiosis; SCFA, bile acid, tryptophan, and sphingolipid metabolites; antioxidants and antimicrobials; and bacterial energy substrates. Further study is warranted to determine the long-term clinical ramifications of differences in antibiotic-induced dysbiosis and dysmetabolism between dogs administered antibiotics alone vs. in combination

\section{REFERENCES}

1. McFarland LV. Antibiotic-associated diarrhea: epidemiology, trends, and treatment. Future Microbiol. (2008) 3:563-78. doi: 10.2217/17460913. 3.5 .563

2. Stokes JE, Price JM, Whittemore JC. Randomized, controlled, crossover trial of prevention of clindamycin-induced gastrointestinal signs using a synbiotic in healthy research cats. J Vet Intern Med. (2017) 31:140613. doi: $10.1111 /$ jvim. 14795

3. Torres-Henderson C, Summers S, Suchodolski J, Lappin MR. Effect of Enterococcus faecium strain SF68 on gastrointestinal signs and fecal microbiome in cats administered amoxicillin-clavulanate. Topics Companion Anim Med. (2017) 32:104-8. doi: 10.1053/j.tcam.2017.11.002

4. Whittemore JC, Stokes JE, Laia NL, Price JM, Suchodolski JS. Short and long-term effects of a synbiotic on clinical signs, the fecal microbiome, with synbiotics. Pending those studies, administration of a synbiotic combination $1-2 \mathrm{~h}$ after each antibiotic dosage is warranted to minimize AAGS as well as derangements in the fecal microbiome and metabolome.

\section{DATA AVAILABILITY STATEMENT}

The datasets presented in this study can be found in online repositories. The names of the repository/repositories and accession number(s) can be found at: https://www.ncbi.nlm. nih.gov/, SRP165850 and https://www.metabolomicsworkbench. org/, 10.21228/M8RH7J, Project ID: PR001013.

\section{ETHICS STATEMENT}

The animal study was reviewed and approved by Institutional Animal Care and Use Committee of the University of Tennessee, Knoxville (protocol 2544).

\section{AUTHOR CONTRIBUTIONS}

JW: Developed the hypothesis and study design. JW and TM: Organized and conducted the experiment. JW, JP, and JS: Interpreted and analyzed the results. JW, JP, TM, and JS: Wrote and revised the manuscript. All authors contributed to the article and approved the submitted version.

\section{FUNDING}

This project was supported by grant 27C-1703 from Nutramax Laboratories Veterinary Sciences, Inc., Lancaster, SC. The funders had no involvement in the design or performance of the study, writing of the manuscript, or the decision to submit the manuscript for publication.

\section{SUPPLEMENTARY MATERIAL}

The Supplementary Material for this article can be found online at: https://www.frontiersin.org/articles/10.3389/fvets. 2021.665713/full\#supplementary-material and metabolomic profiles in healthy research cats receiving clindamycin: a randomized, controlled trial. PeerJ. (2018) 6:e5130. doi: 10.7717/peerj.5130

5. Whittemore JC, Moyers TD, Price JM. Randomized, controlled, crossover trial of prevention of antibiotic-induced gastrointestinal signs using a synbiotic mixture in healthy research dogs. J Vet Internal Med. (2019) 33:161926. doi: $10.1111 /$ jvim. 15553

6. Whittemore JC, Stokes JE, Price JM, Suchodolski JS. Effects of a synbiotic on the fecal microbiome and metabolomic profiles of healthy research cats administered clindamycin: a randomized, controlled trial. Gut Microbes. (2019) 10:521-39. doi: 10.1080/19490976.2018. 1560754

7. Pilla R, Gaschen FP, Barr JW, Olson E, Honneffer J, Guard BC, et al. Effects of metronidazole on the fecal microbiome and metabolome: in healthy dogs. J Vet Internal Med. (2020) 34:1853-66. doi: 10.1111/jvim.15871

8. Whittemore J. Data from: Antibiotic Synbiotic Dog Microbiome (2019). 
9. AlShawaqfeh MK, Wajid B, Minamoto Y, Markel M, Lidbury JA, Steiner JM, et al. A dysbiosis index to assess microbial changes in fecal samples of dogs with chronic inflammatory enteropathy. FEMS Microbiol Ecol. (2017) 93:fix136. doi: 10.1093/femsec/fix136

10. Whittemore J. Data from: Effects of Synbiotic Administration on Fecal Microbiome and Metabolomic Profiles of Dogs Receiving Antibiotics. The Metabolomics Workbench (2020). doi: 10.21228/M8RH7J

11. Igarashi $\mathrm{H}$, Maeda $\mathrm{S}$, Ohno $\mathrm{K}$, Horigome A, Odamaki $\mathrm{T}$, Tsujimoto $\mathrm{H}$. Effect of oral administration of metronidazole or prednisolone on fecal microbiota in dogs. PLoS ONE. (2014) 9:e107909. doi: 10.1371/journal.pone. 0107909

12. Manchester AC, Webb CB, Blake AB, Sarwar F, Lidbury JA, Steiner JM, et al. Long-term impact of tylosin on fecal microbiota and fecal bile acids of healthy dogs. J Vet Internal Med. (2019) 33:2605-17. doi: 10.1111/jvim.15635

13. Bresciani F, Minamoto Y, Suchodolski JS, Galiazzo G, Vecchiato CG, Pinna C, et al. Effect of an extruded animal protein-free diet on fecal microbiota of dogs with food-responsive enteropathy. J Vet Internal Med. (2018) 32:190310. doi: 10.1111/jvim.15227

14. Giaretta PR, Rech RR, Guard BC, Blake AB, Blick AK, Steiner JM, et al. Comparison of intestinal expression of the apical sodium-dependent bile acid transporter between dogs with and without chronic inflammatory enteropathy. J Vet Internal Med. (2018) 32:1918-26. doi: 10.1111/jvim.15332

15. Guard BC, Honneffer JB, Jergens AE, Jonika MM, Toresson L, Lawrence YA, et al. Longitudinal assessment of microbial dysbiosis, fecal unconjugated bile acid concentrations, and disease activity in dogs with steroid-responsive chronic inflammatory enteropathy. J Vet Internal Med. (2019) 33:1295305. doi: 10.1111/jvim.15493

16. Chaitman J, Ziese A-L, Pilla R, Minamoto Y, Blake AB, Guard BC, et al. Fecal microbial and metabolic profiles in dogs with acute diarrhea receiving either fecal microbiota transplantation or oral metronidazole. Front Vet Sci. (2020) 7:192. doi: $10.3389 /$ fvets.2020.00192

17. Kilian E, Suchodolski JS, Hartmann K, Mueller RS, Wess G, Unterer S. Long-term effects of canine parvovirus infection in dogs. PLoS ONE. (2018) 13:e0192198. doi: 10.1371/journal.pone.0192198

18. Llewellyn SR, Britton GJ, Contijoch EJ, Vennaro OH, Mortha A, Colombel J$\mathrm{F}$, et al. Interactions between diet and the intestinal microbiota alter intestinal permeability and colitis severity in mice. Gastroenterology. (2018) 154:103746.e1032. doi: 10.1053/j.gastro.2017.11.030

19. Pilla R, Suchodolski JS. The role of the canine gut microbiome and metabolome in health and gastrointestinal disease. Front Vet Sci. (2020) 6:498. doi: 10.3389/fvets.2019.00498

20. Duboc H, Rajca S, Rainteau D, Benarous D, Maubert MA, Quervain E, et al. Connecting dysbiosis, bile-acid dysmetabolism and gut inflammation in inflammatory bowel diseases. Gut. (2013) 62:531-9. doi: 10.1136/gutjnl-2012-302578

21. Agus A, Planchais J, Sokol H. Gut microbiota regulation of tryptophan metabolism in health and disease. Cell Host Microbe. (2018) 23:71624. doi: 10.1016/j.chom.2018.05.003

22. Abdel Hadi L, Di Vito C, Riboni L. Fostering inflammatory bowel disease: sphingolipid strategies to join forces. Mediators Inflammation. (2016) 2016:3827684. doi: 10.1155/2016/3827684
23. Manuja R, Sachdeva S, Jain A, Chaudhary J. A comprehensive review on biological activities of P-hydroxy benzoic acid and its derivatives. Int J Pharm Sci Rev Res. (2013) 22:109-15. Avaiable online at: https://globalresearchonline. net/journalcontents/v22-2/20.pdf

24. Alam MA, Subhan N, Hossain H, Hossain M, Reza HM, Rahman MM, et al. Hydroxycinnamic acid derivatives: a potential class of natural compounds for the management of lipid metabolism and obesity. Nutr Metab. (2016) 13:27. doi: 10.1186/s12986-016-0080-3

25. Ferreyra JA, Ng KM, Sonnenburg JL. The enteric two-step: nutritional strategies of bacterial pathogens within the gut. Cell Microbiol. (2014) 16:9931003. doi: $10.1111 / \mathrm{cmi} .12300$

26. Ormsby MJ, Logan M, Johnson SA, McIntosh A, Fallata G, Papadopoulou R, et al. Inflammation associated ethanolamine facilitates infection by Crohn's disease-linked adherent-invasive Escherichia coli. EBioMedicine. (2019) 43:325-32. doi: 10.1016/j.ebiom.2019. 03.071

27. Bertin Y, Girardeau JP, Chaucheyras-Durand F, Lyan B, Pujos-Guillot E, Harel J, et al. Enterohaemorrhagic Escherichia coli gains a competitive advantage by using ethanolamine as a nitrogen source in the bovine intestinal content. Environ Microbiol. (2011) 13:365-77. doi: 10.1111/j.1462-2920.2010. 02334.x

28. Dogan B, Suzuki H, Herlekar D, Sartor RB, Campbell BJ, Roberts CL, et al. Inflammation-associated adherent-invasive Escherichia coli are enriched in pathways for use of propanediol and iron and M-cell translocation. Inflamm Bowel Dis. (2014) 20:1919-32. doi: 10.1097/MIB.0000000000000183

29. Suchodolski JS, Dowd SE, Westermarck E, Steiner JM, Wolcott RD, Spillman $\mathrm{T}$, et al. The effect of the macrolide antibiotic tylosin on microbial diversity in the canine small intestine as demonstrated by massive parallel $16 \mathrm{~S}$ rRNA gene sequencing. BMC Microbiol. (2009) 9:210. doi: 10.1186/14712180-9-210

30. Carlos N, Tang Y-W, Pei Z. Pearls and pitfalls of genomics-based microbiome analysis. Emerg Microbes Infect. (2012) 1:e45. doi: 10.1038/emi.2012.41

31. Tkacz A, Hortala M, Poole PS. Absolute quantitation of microbiota abundance in environmental samples. Microbiome. (2018) 6:110. doi: 10.1186/s40168-018-0491-7

Conflict of Interest: JW and JS have received past honoraria from Nutramax Laboratories Veterinary Sciences, Inc. for development of educational materials and public speaking.

The remaining authors declare that the research was conducted in the absence of any commercial or financial relationships that could be construed as a potential conflict of interest.

Copyright (C) 2021 Whittemore, Price, Moyers and Suchodolski. This is an open-access article distributed under the terms of the Creative Commons Attribution License (CC $B Y)$. The use, distribution or reproduction in other forums is permitted, provided the original author(s) and the copyright owner(s) are credited and that the original publication in this journal is cited, in accordance with accepted academic practice. No use, distribution or reproduction is permitted which does not comply with these terms. 